\title{
3-D geomechanical-numerical model of the contemporary crustal stress state in the Alberta Basin (Canada)
}

\author{
K. Reiter ${ }^{1,2}$ and O. Heidbach ${ }^{1}$ \\ ${ }^{1}$ GFZ German Research Centre for Geosciences, Telegrafenberg, 14473 Potsdam, Germany \\ ${ }^{2}$ University of Potsdam, Institute of Earth and Environmental Science, Karl-Liebknecht-Straße 24-25, \\ 14476 Potsdam-Golm, Germany \\ Correspondence to: K. Reiter (reiter@gfz-potsdam.de)
}

Received: 31 July 2014 - Published in Solid Earth Discuss.: 20 August 2014

Revised: 16 October 2014 - Accepted: 19 October 2014 - Published: 25 November 2014

\begin{abstract}
In the context of examining the potential usage of safe and sustainable geothermal energy in the Alberta Basin, whether in deep sediments or crystalline rock, the understanding of the in situ stress state is crucial. It is a key challenge to estimate the 3-D stress state at an arbitrarily chosen point in the crust, based on sparsely distributed in situ stress data.
\end{abstract}

To address this challenge, we present a large-scale 3-D geomechanical-numerical model $(700 \mathrm{~km} \times 1200 \mathrm{~km} \times 80 \mathrm{~km})$ from a large portion of the Alberta Basin, to provide a 3-D continuous quantification of the contemporary stress orientations and stress magnitudes. To calibrate the model, we use a large database of in situ stress orientation (321 $\left.S_{\mathrm{Hmax}}\right)$ as well as stress magnitude data $\left(981 S_{\mathrm{V}}, 1720 S_{\mathrm{hmin}}\right.$ and $\left.2(+11) S_{\mathrm{Hmax}}\right)$ from the Alberta Basin. To find the best-fit model, we vary the material properties and primarily the displacement boundary conditions of the model. This study focusses in detail on the statistical calibration procedure, because of the large amount of available data, the diversity of data types, and the importance of the order of data tests.

The best-fit model provides the total 3-D stress tensor for nearly the whole Alberta Basin, and allows estimation of stress orientation and stress magnitudes in advance of any well. First-order implications for the well design and configuration of enhanced geothermal systems are revealed. Systematic deviations of the modelled stress from the in situ data are found for stress orientations in the Peace River and the Bow Island Arch as well as for leak-off test magnitudes.

\section{Motivation}

The estimation of the in situ stress state in the upper crust, in addition to the understanding of earthquake cycles and plate tectonics, is crucial for exploration and production of energy resources. These include geothermal energy, hydrocarbons, $\mathrm{CO}_{2}$ sequestration (carbon capture storage - CCS) and geotechnical subsurface constructions such as mines, tunnels, interim storage sites for natural gas and nuclear waste deposits. Reliable estimates of orientation and magnitude of the crustal stress field are desired before drilling. This is important in terms of well stability (e.g. Bell and McLellan, 1995; Peska and Zoback, 1995), but is also related to the well configuration of several corresponding wells (e.g. Bell and McLellan, 1995) in the case of reservoir stimulation by hydraulic fracturing. This is important in geothermal reservoirs (enhanced geothermal systems - EGS) (Legarth et al., 2005; Wessling et al., 2009) and issues of inadequate understanding of the spatial stress pattern (e.g. Brown, 2009; Duchane and Brown, 2002). This is also true for hydrocarbon reservoirs or the evaluation of nuclear waste repositories (e.g. Fuchs and Müller, 2001; Gunzburger and Magnenet, 2014; Heidbach et al., 2013).

The stress tensor and its components are not to be measured directly, but there are several stress indicators which allow estimation of several components of the stress tensor (e.g. Ljunggren et al., 2003; Schmitt et al., 2012; Zang and Stephansson, 2010). The following components of the stress tensor are potentially available: the azimuth of the maximum (or minimum) horizontal stress $\left(S_{\mathrm{H} \max }\right)$, the vertical stress magnitude $\left(S_{\mathrm{V}}\right)$, as well as the magnitudes of the maximum and minimum horizontal stress $\left(S_{\mathrm{hmin}}\right.$ and $\left.S_{\mathrm{H} \max }\right)$. However, 
reliable estimation of the $S_{\mathrm{Hmax}}$ magnitude remains difficult, as only shallow in situ stress estimations are available, or numerous assumptions have to be made that impose high uncertainties. Furthermore, stress information is sparse, and extraor inter-polation of a few data records to the area or depth of interest is necessary.

However, stress estimation via interpolation techniques becomes particularly questionable in the case of structural inhomogeneities like faults, detachments (Bell and McLellan, 1995; Röckel and Lempp, 2003; Roth and Fleckenstein, 2001; Yassir and Bell, 1994), or varying material properties (Roche et al., 2013; Warpinski, 1989). Furthermore, drilling down to a geothermal reservoir requires reaching greater depths, as available measurements are delivered in the context of hydrocarbon production. For example, in Alberta, deeper parts of the basin or the upper basement are the target depths for EGS (e.g. Hofmann et al., 2014; Majorowicz and Grasby, 2010a, b; Weides et al., 2013, 2014). Therefore, estimation of the stress state, especially at greater depths, is a challenge prior to drilling.

An alternative approach to estimating the 3-D stress state is geomechanical-numerical modelling. This method has the advantage of incorporating structural and material inhomogeneities that impose local to regional changes on the stress field. There are several studies on tectonic plate scale stress orientation patterns in 2-D (e.g. Coblentz and Richardson, 1996; Dyksterhuis et al., 2005; Humphreys and Coblentz, 2007; Jarosinski et al., 2006), large-scale (regional) models in 3-D (Buchmann and Connolly, 2007; Hergert and Heidbach, 2011; Parsons, 2006), as well as local (reservoir-scale) 3-D models (e.g. Fischer and Henk, 2013; Heidbach et al., 2013; Henk, 2005; Orlic and Wassing, 2012; Van Wees et al., 2003). Modelling of the contemporary stress field mainly depends on the structural model, the material properties, the initial stress state and the applied displacement boundary conditions. However, the reliability of such models depends strongly on the model calibration towards in situ stress data. Usually, there are little in situ stress data available for model calibration in published studies (e.g. Buchmann and Connolly, 2007; Fischer and Henk, 2013; Heidbach et al., 2013; Hergert and Heidbach, 2011), which rules out any statistical validation.

The Alberta Basin is a study area with well-understood structures and material properties, and a large collection of in situ stress data. We use this information to build a 3-D geomechanical-numerical model of the Alberta Basin and surroundings with an extent of $1200 \mathrm{~km} \times 700 \mathrm{~km}$ down to a depth of $80 \mathrm{~km}$. The goal is to get the full tensor of the contemporary undisturbed stress state, called stress model in the following. These are $981 S_{\mathrm{V}}$ magnitude data, 321 $S_{\mathrm{Hmax}}$ azimuth data, $1720 S_{\mathrm{hmin}}$ magnitudes, and 2 measured (overcoring) and 11 calculated $S_{\mathrm{Hmax}}$ magnitudes within the model region. There is no other basin with a comparable range of available in situ stress data (Bell and Grasby, 2012). The availability of very good stress data allows for the cali- bration of the stress model vs. a never-reached diversity, and a number of in situ stress indicators.

The model calibration will be done in three consecutive steps: (1) density of basin infill, using $S_{\mathrm{V}}$ magnitude data, (2) orientation of displacement boundary conditions using $S_{\mathrm{H} \text { max }}$ azimuth data, and (3) magnitudes of displacement boundary conditions (strain) using $S_{\mathrm{hmin}}$ and $S_{\mathrm{H} \max }$ magnitude data. As linear elastic rheology is used for the model, the linear dependency between the two applied strain magnitudes (push and pull) along the outer edges of the model is calculated. This allows, via planar regressions the calculation of the optimal strain magnitudes, providing the best-fit model. The application of the model would be for exploitation of hydrocarbons and more for exploration and design of a geothermal plant in the Alberta Basin. Additionally it may be used in crystalline rocks, mainly in case of necessary hydraulic stimulation. Mistaken investments e.g. parts of the Fenton Hill project (Brown, 2009; Duchane and Brown, 2002) could potentially be avoided with a better previous understanding of the 3-D in situ stress state.

\section{Modelling concept}

\subsection{Model assumptions}

The compilation of stress data in North America by Adams (1987, 1989), Adams and Bell (1991), Bell et al. (1994), Fordjor et al. (1983), Gough et al. (1983), Sbar and Sykes (1973), Zoback and Zoback (1980, 1981, 1989, 1991) and recently by Reiter et al. (2014) resolved that the pattern of $S_{\mathrm{Hmax}}$ orientations is largely uniform over thousands of kilometres. An assumption was that the same forces driving plate tectonics are the major control on the stress field, which is confirmed in first order (e.g. Richardson, 1992; Zoback et al., 1989; Zoback, 1992).

The stress pattern is driven and altered by several stress sources; they are discriminated depending on the scales into first-order $(>500 \mathrm{~km})$, second-order $(100-500 \mathrm{~km})$ and third-order stress sources $(<100 \mathrm{~km})$ (Heidbach et al., 2007, 2010; Müller et al., 1997; Tingay et al., 2005; Zoback, 1992; Zoback and Mooney, 2003). First-order stress sources as the main driving forces are summarized as plate boundary forces, which are ridge push, slab pull, and trench suction, gravity and basal drag by mantle convection. Second-order stress sources are lithospheric flexure, localized lateral density, stiffness and strength contrasts, topography, large fault zones, and lateral contrasts of heat production. Third-order stress sources are local density, stiffness or strength contrasts, basin geometry, basal detachment, incised valleys, and anthropogenic stress changes.

Under the parameters to reproduce the crustal stress field of the Alberta Basin, the model has to be large enough to portray the first- and second-order stress sources. Whereas the first-order stress sources, which control plate tectonic 
motion, are represented by the displacement boundary conditions, the second- and third-order stress sources are represented by the model geometry. This is possible when structures are known and convertible to the model. As inhomogeneous topography and mass distribution within the lithosphere have a major impact on the stress orientation (Camelbeeck et al., 2013; Ghosh et al., 2009; Humphreys and Coblentz, 2007; Naliboff et al., 2012), it is crucial to incorporate the major structural units into the crust and upper mantle in the model geometry.

Linear elastic material properties are an accurate approximation as long as the strain $(\boldsymbol{\epsilon})$ is small enough, and no failure occurs. This might be assumed for the Alberta Basin, which is seismically relatively quiescent. Documented earthquakes are usually restricted to the Rocky Mountains, foothills, and suspected man-made clustered events (e.g. Baranova et al., 1999; Schultz et al., 2014).

Our focus is the Alberta Basin and the uppermost basement below the basin due to our key interest in the investigation of the potential usability of deep geothermal energy (EGS). Furthermore, the calibration data are from the sediments up to a depth of about $5 \mathrm{~km}$ when no deeper stress indicators are available. Exceptions to this are three $S_{\text {Hmax }}$ azimuths, derived from focal mechanism solutions.

Viscous rock deformation, acceleration, changing pore pressures as well as other thermal effects influence the stress state, but as we strive to model the contemporary undisturbed total stress tensor (stress model), these processes are assumed to have only marginal influence, and are disregarded in the model. We assume that the following model assumptions are sufficient to estimate the contemporary 3-D stress state within the Alberta Basin and upper basement:

- large-scale geometry of the model down to the upper mantle is crucial (main structural units only).

- linear elastic material properties are used.

- gravity as the body force.

- the lateral displacement boundary conditions of the model are a parameterization of ongoing plate tectonic motion, effects of lateral density contrasts (gravitational potential energy) of outside of the model, and remnant stresses from terminated tectonic processes.

Due to the complex structures and inhomogeneous materials properties, an analytical solution cannot be estimated. Thus, we use for the discrete solution the finite element method (FEM), as it allows us to use unstructured meshes, for a good representation of the 3-D model structure. With these assumptions, the model is described with the partial differential equations of the equilibrium of forces:

$\frac{\partial \boldsymbol{\sigma}_{i j}}{\partial x_{j}}+\rho x_{i}=0$

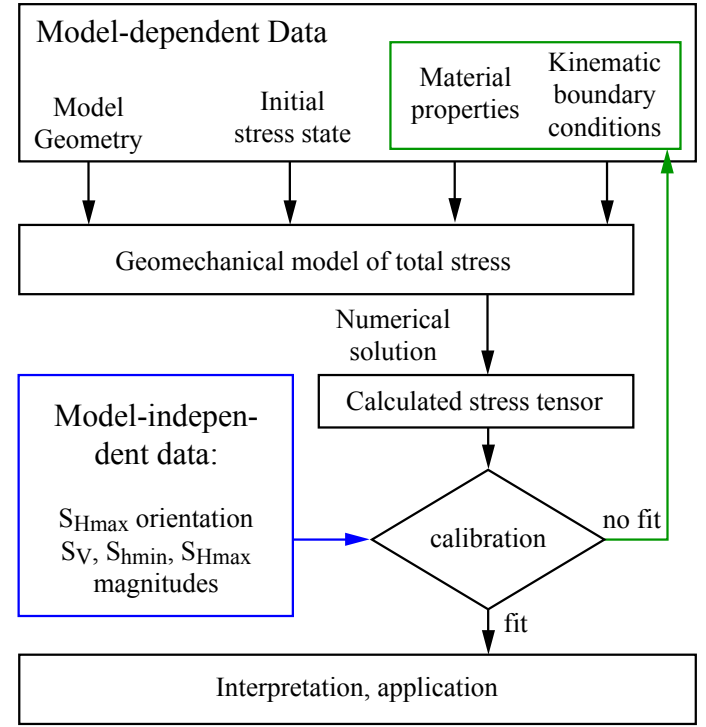

Figure 1. Sketch of the general workflow. The geomechanical model is prepared based on the model geometry, the material properties, the variable displacement boundary conditions and the initial stress state. The numerically modelled total stress tensor is calibrated on model-independent in situ stress data until the model fits the calibration data.

where $\partial \boldsymbol{\sigma}_{i j}$ is the change in total stress, $\partial x$ the change in length, and $\rho x$ represents the weight of the rock section $(\rho=$ density).

After model design (structural model) and definition of material properties (Poisson's ratio, Young's modulus and density), the partial differential equation (Eq. 1) can be calculated within given displacement boundary conditions. The latter will be varied to find the best-fit model. This is the stress model together with material properties and displacement boundary conditions, which deliver the best-fit for all in situ stress data.

\subsection{General workflow of model calibration}

Generally, a model has to be calibrated before application or interpretation. The general concept, independent of the technical context, is to test the model's outcome vs. in situ data. Such data are called model-independent data, in contrast to model-dependent data, which are used to generate the model.

In this study, the lithological and tectonic structures, the rheology, the body force, the initial stress state, and the displacement boundary conditions, are the model-dependent data (Fig. 1). Based on these data, the structural model is defined, which is discretized to a (unstructured) mesh and assembled together with the material properties, body forces, the boundary conditions, and the initial stress state. Available in situ stress data are the model-independent data. These are the $S_{\mathrm{V}}$ magnitudes, the $S_{\mathrm{Hmax}}$ azimuth data, and $S_{\mathrm{hmin}}$ and $S_{\text {Hmax }}$ magnitudes. The modelled stress tensor is tested 
against the in situ data. When one data set is tested successfully, the next data set is used in the next calibration step. Otherwise, the material properties or boundary conditions are optimized as long as the test is successful.

First, the stress model is tested vs. in situ $S_{\mathrm{V}}$ magnitudes, to conclude estimation of density (material properties and body force). In the second step, the $S_{\mathrm{Hmax}}$ orientation is tested to determine the orientation of applied displacement boundary conditions. In the final step, $S_{\mathrm{hmin}}$ and $S_{\text {Hmax }}$ magnitudes are used to calibrate the applied magnitudes of the displacement boundary conditions. When all model-independent data sets are tested successfully, the bestfit model is found and is a subject of further use (interpretation and application).

The model-dependent data, construction and compilation process of the geomechanical model are described in Sect. 3, whereas the model-independent data are introduced in Sect. 4. The calibration procedure is presented in detail in Sect. 5. Finally, the discussion can be found in Sect. 6 .

\section{Model setup}

\subsection{Geometry of the Alberta Basin}

\subsubsection{Tectonic and sedimentary history of the Alberta Basin}

The Alberta Basin (Fig. 2) occupies a large portion of the much larger Western Canada Sedimentary Basin (WCSB). Starting from the northeast, clockwise it is bounded by the Canadian Shield, the Bow Island Arch, the Rocky Mountains and the Tathlina High in the north. The crystalline basement of the WCSB and, implicitly, of the superposed Alberta Basin, is the North American craton exposed by erosion to the northeast as the Canadian Shield (Boerner et al., 2000; Flowers et al., 2012; Hoffman, 1989; Ross et al., 1994, 2000). The main structural units of the Alberta basement are the Buffalo Head Terrane (Aulbach et al., 2004), the Taltson Magmatic Zone (e.g. Chacko et al., 2000), the Hearne Province (Hajnal et al., 2005) and the Trans-Hudson Orogen (e.g. Corrigan et al., 2005; Németh et al., 2005) and other smaller units, which welded together between 1.8 and $2.0 \mathrm{Ga}$. There are two important lineaments, the Snowbird Tectonic Zone (STZ - Ross et al., 2000, and references therein) and the Great Slave Lake Shear Zone (GLS - Sami and James, 1993), and their continuation (Hay River fault zone).

Sediments were deposited in the basin, interrupted by a few discontinuities during the whole Phanerozoic (Mossop and Shetsen, 1994a, Chapter 6-26). Mainly shelf sediments deposited onto the craton as recently as the Upper Jurassic. At that time, sedimentation character changed, and the basin developed to a rapidly subsiding fore-deep trough (Poulton et al., 1994). Mature sediments were previously derived from the northeast, and changed to less mature sedi-

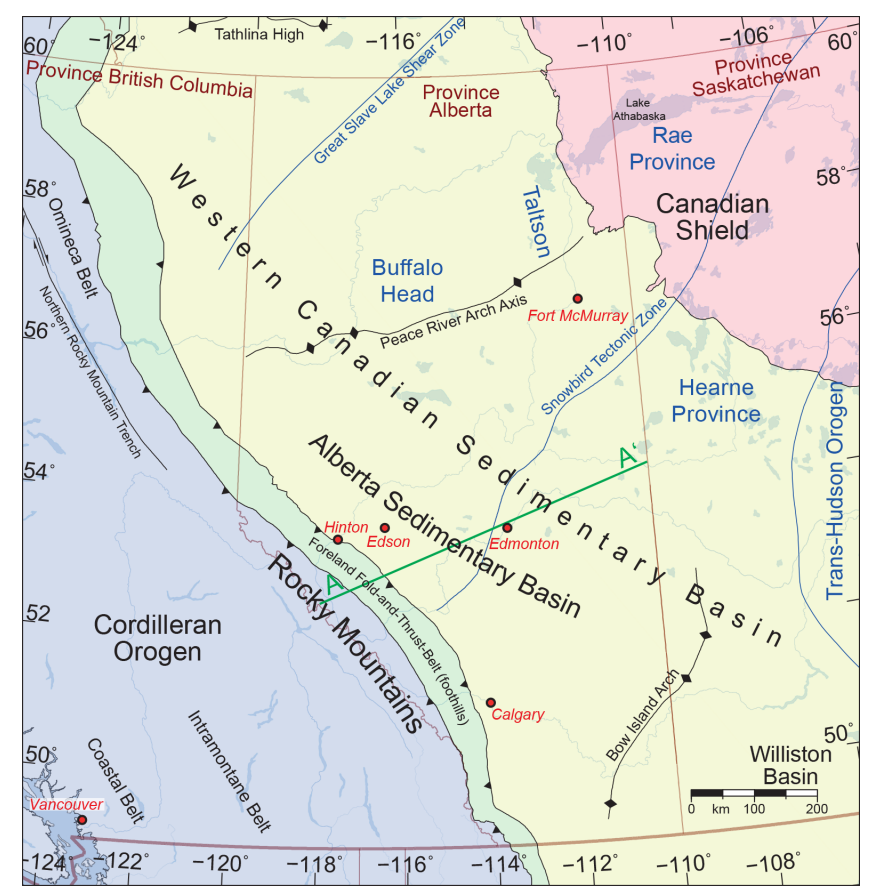

Figure 2. Tectonic map of Alberta and surroundings displaying the important structural features. Blue lines and labels indicate Precambrian structures in the basement. Provincial boundaries and areas are indicated by reddish-brown colours, and tectonic features are labelled in black. The trace of the cross section in Fig. 3 is indicated by a green line. The map is modified and redrawn after Wright et al. (1994).

ments derived from the west. The change to terrestrial deposits in Early Cretaceous (Smith, 1994) coincides with first the Ominicean Orogeny, and later the Lamariden Orogeny (Porter et al., 1982; Price, 1981; Wright et al., 1994). Jurassic to Palaeocene strata mainly deposited in the western part of the Alberta Basin and have been incorporated in the Rocky Mountains fold-and-thrust belt (foothills and front ranges - Fig. 3). This is bound farther west (main ranges) in British Columbia by the Rocky Mountain Trench. The final shape of the Alberta foreland basin developed by downward flexing of the Canadian Shield due to lithospheric loading and isostatic flexure in a retro-arc setting (Leckie and Smith, 1992; English and Johnston, 2004), together with the sediments derived from the developing Canadian Cordillera (Gabrielse and Yorath, 1989). The Alberta Basin consists of a nearly undeformed sedimentary wedge (Fig. 3) that increases in thickness from zero at the Canadian Shield to approximately $5500 \mathrm{~m}$ near the fold-and-thrust belt. The overall wedge shape in the Alberta Basin, perpendicular to the Rocky Mountains, is quite homogeneous from northwest to southeast.

Only the Peace River Arch close to the Rocky Mountains is striking within the homogeneous wedge, which is indicated by several geophysical investigations. There are several 


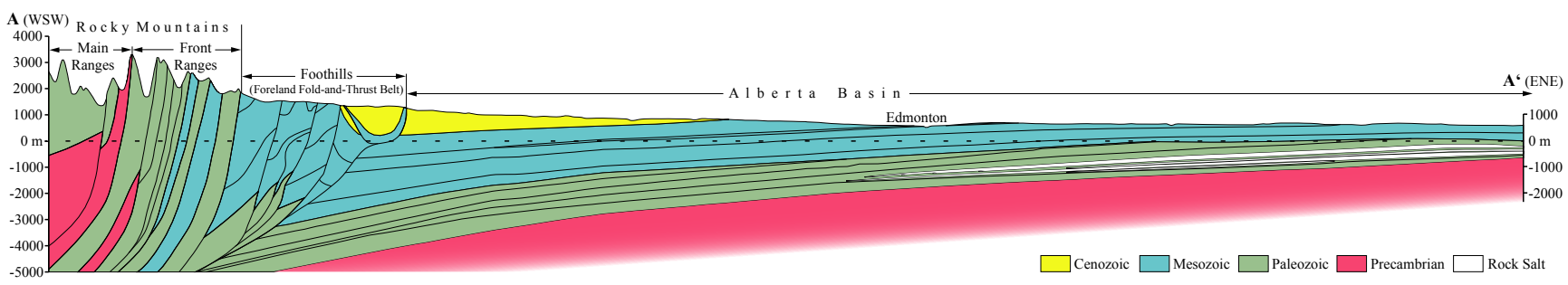

Figure 3. Cross section across Alberta in west-southwest to east-northeast orientation; the trace is highlighted in Figs. 2 and 4 . Visible is the Alberta Basin as a wedge-shaped retro-arc foreland basin, together with parts of the Rocky Mountains and the foreland fold-and-thrust belt (foothills) in between. The rock units are roughly indicated by the stratigraphic age. Additional thick rock salt units are indicated separately, because of their potential to detach the stress field. The vertical exaggeration is 10 times, redrawn after Hamilton et al. (1999).

explanations: an elevated Precambrian basement (Bell and Babcock, 1986; Bell, 1996b; Bell and Grasby, 2012; Halchuk and Mereu, 1990), the occurrence of mafic sills which intruded in the upper crust of the Peace River Arch (Eaton et al., 1999), and/or lateral heterogeneities (transfer zone or local rheological properties in Bell and McCallum, 1990), a softer inclusion (Dusseault and Yassir, 1994), or crustal thinning caused by extension (Bouzidi et al., 2002).

\subsubsection{Model geometry}

The structural-geological model is of major importance, and is prepared with the GOCAD ${ }^{\circledR}$ 3-D geomodelling system. Faults and lithological boundaries are defined as discrete triangulated surfaces. These are built based on points (stratigraphic borehole data and seismic data), curves (seismic and interpreted cross sections, lineaments from the geological map) or point clouds that describe surfaces (DEM). During surface generation, data are honoured as soft or hard constrained, depending on their quality (e.g. Ross et al., 2004). The roughnesses of the surfaces are polished with the discrete smoothing interpolation (DSI) algorithm (Mallet, 1992, 2002).

The model box of Alberta, indicated in Fig. 4, is oriented parallel or perpendicular to the observed basin structure (Fig. 2), the orientation of $S_{\mathrm{Hmax}}$ (e.g. Bell et al., 1994; Reiter et al., 2014, see rose diagram in Fig. 4), the wedge shape of the Alberta Basin (Fig. 3), the thermally defined Cordillera-Craton boundary (Hyndman et al., 2009) and the overall plate motion of the North American Craton, measured by GPS (Henton et al., 2006; Mazzotti et al., 2011).

The model has a southwest-to-northeast striking extent of $700 \mathrm{~km}, 1200 \mathrm{~km}$ in the northwest-to-southeast direction (Fig. 4), and $80 \mathrm{~km}$ in depth. For the definition of the model geometry, it was necessary to choose the geometrically relevant structures, strength contrasts or density variations. These can potentially affect the stress field, while considering limitations of the possible number of finite elements. The main structural units are the mantle, the crustal basement, the sedimentary basin, the foothills, the Rocky Mountains and the Elk Point evaporates within the basin, due to their

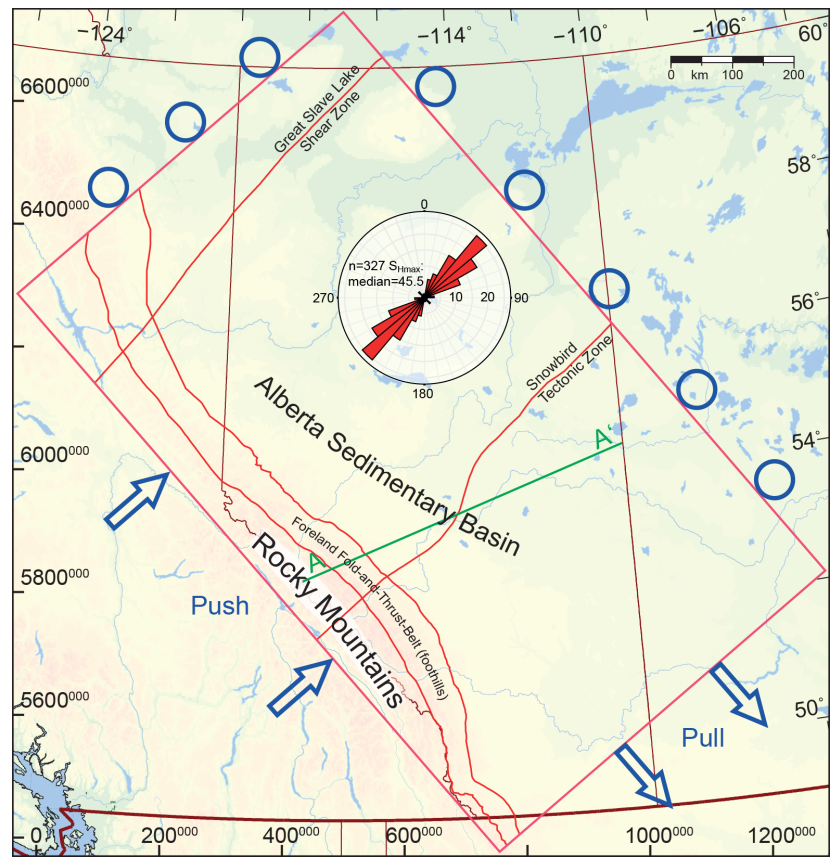

Figure 4. Map of Alberta with the model extent (red box) combined with the model features. Implemented are the main structural features (red lines), which are the front of the Rocky Mountains and the foothills, respectively, as well as the Snowbird Tectonic Zone and the Great Slave Lake Shear Zone. For comparison, see the tectonic map (Fig. 2). Push and pull along model sides and the allowed lateral motion are indicated by blue arrows and circles, respectively. The mean orientation of $S_{\mathrm{Hmax}}$ is indicated by a rose diagram; note that stress orientation is parallel and orthogonal, respectively, to the model box. The trace of the cross section in Fig. 3 is indicated by the green line.

potential to detach the stresses of the supra-salt units from the sub-salt units. Furthermore, the Snowbird tectonic zone and the Great Slave shear zone are incorporated, and cut the basement and the sediments.

The deepest implemented boundary is the Mohorovičić discontinuity (Moho) as the crust-mantle transition. We use various geophysical data to define the Moho topography 


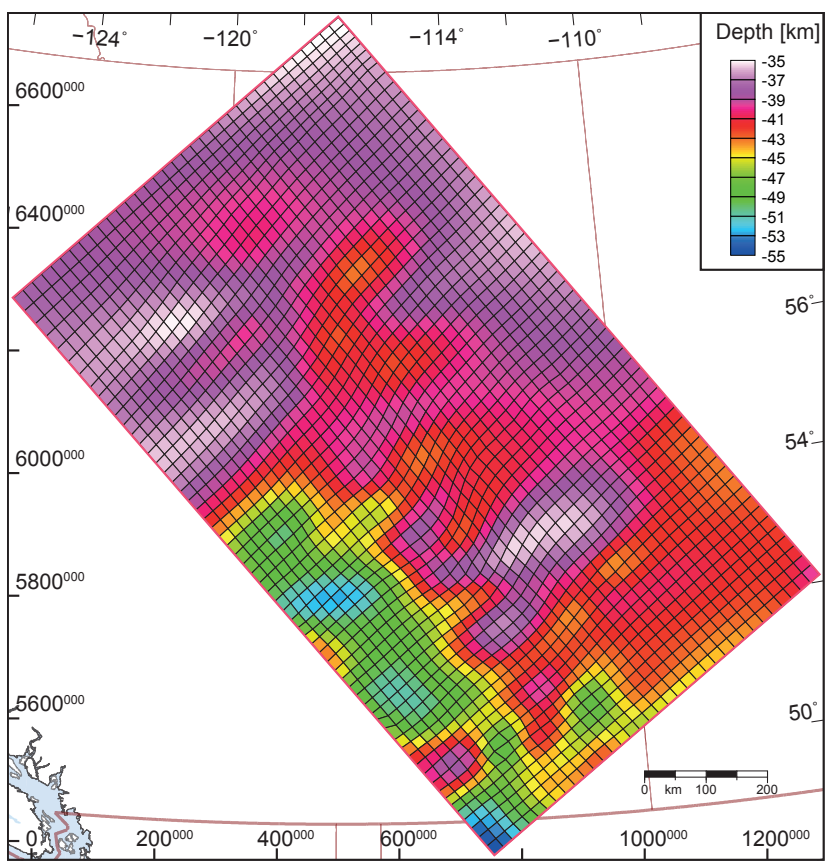

Figure 5. Topography of the Mohorovičić discontinuity (Moho) within the model box. The map extent is indicated by geographical coordinates (top and right) and by UTM coordinates from zone 11 (left and bottom). The mesh size $(\sim 20 \mathrm{~km})$ at that depth is indicated by black lines.

(Fig. 5) by directional kriging. These are data from seismic refraction studies (Bouzidi et al., 2002; Burianyk et al., 1997; Clowes et al., 2002; Fernández-Viejo and Clowes, 2003; Halchuk and Mereu, 1990; Németh et al., 1996, 2005; Spence and McLean, 1998; Welford et al., 2001; Zelt and White, 1995) and from teleseismic studies (Gu et al., 2011; Shragge et al., 2002).

The basement top (Fig. 6) is defined as the boundary between the basement (southwestern continuation of the Canadian Shield) and the sedimentary basin. It is constructed by DSI, based on 7257 well data available from the Alberta Geological Survey (AGS).

The strata overlying the Precambrian basement are subdivided into the Rocky Mountains, the foreland fold-and-trust belt (foothills) and the sediments within the basin (Fig. 7). The first set consists of allochthonous Palaeozoic strata, whereas the foothills consists of the same stack of sediments from the entire Phanerozoic, deposited in the Western Canadian Sedimentary Basin. For a definition of the boundary between these parts, geological maps and interpreted cross sections were used (Mossop and Shetsen, 1994b; Price, 1994; Wright et al., 1994).

Salt deposits within the sedimentary column have the possibility to geomechanically detach the stresses in the upper rock units from the long wave-length stresses at depth (Bell, 1993; Roth and Fleckenstein, 2001; Röckel and Lempp, 2003; Tingay et al., 2005). The Devonian Elk Point Group

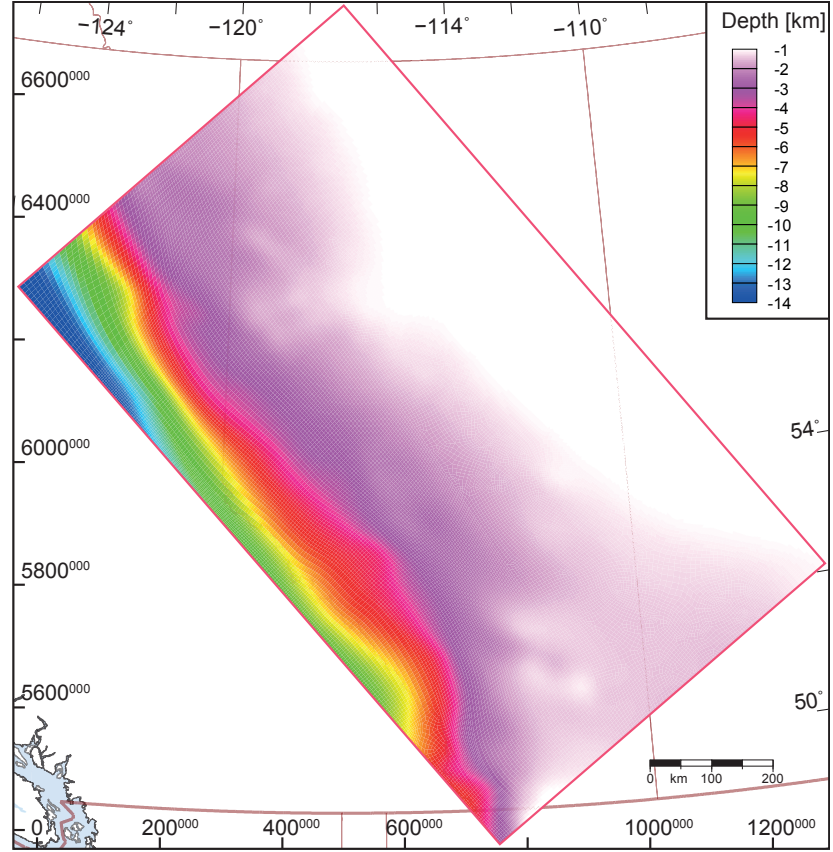

Figure 6. Topography of the basement top is shown within the model box. The map extent is indicated by geographical coordinates (top and right) and by UTM coordinates from zone 11 (left and bottom).

contains several salt deposits (Grobe, 2000; Meijer Drees, 1994). These up to $380 \mathrm{~m}$ thick deposits (Figs. 3 and 7) have been recognized within five stratigraphic formations. They are ordered from oldest to youngest: Lower Lotsberg, Upper Lotsberg, Cold Lake, Prairie Evaporate and Hubbard Evaporate salts. The Elk Point evaporates are separated from the other basin sediments (Mossop and Shetsen, 1994a, Chapter 8-26) as an independent unit; evaporate strata with a thickness of $\geq 100 \mathrm{~m}$ are used based on data from Grobe (2000). All these interfaces are also generated with the DSI algorithm. Finally, the model box is completed with the digital elevation model (DEM) from the USGS (2008).

\subsubsection{Model discretization into finite elements}

Our key goal is to model the contemporary 3-D stress state within the basin and in the upper part of the basement. To reproduce the thin rock salt layer within the basin, it was necessary to have a minimum element amount of six elements within the basin in the $z$ direction. This results in a vertical resolution of about 200 to $800 \mathrm{~m}$ for the upper model parts (Fig. 8). In the $x$ and $y$ directions, the resolution within the basin and the upper basement is about $5000 \mathrm{~m}$. The element thickness increases with depth within the basement. In deeper parts $(-25$ to $-80 \mathrm{~km})$, the resolution is approximately $20 \mathrm{~km}$ in all directions (Fig. 5). The whole model is discretized into 349690 hexahedrons, 4188 tetrahedrons, 552 pyramids and 474 prism elements with linear approximation 


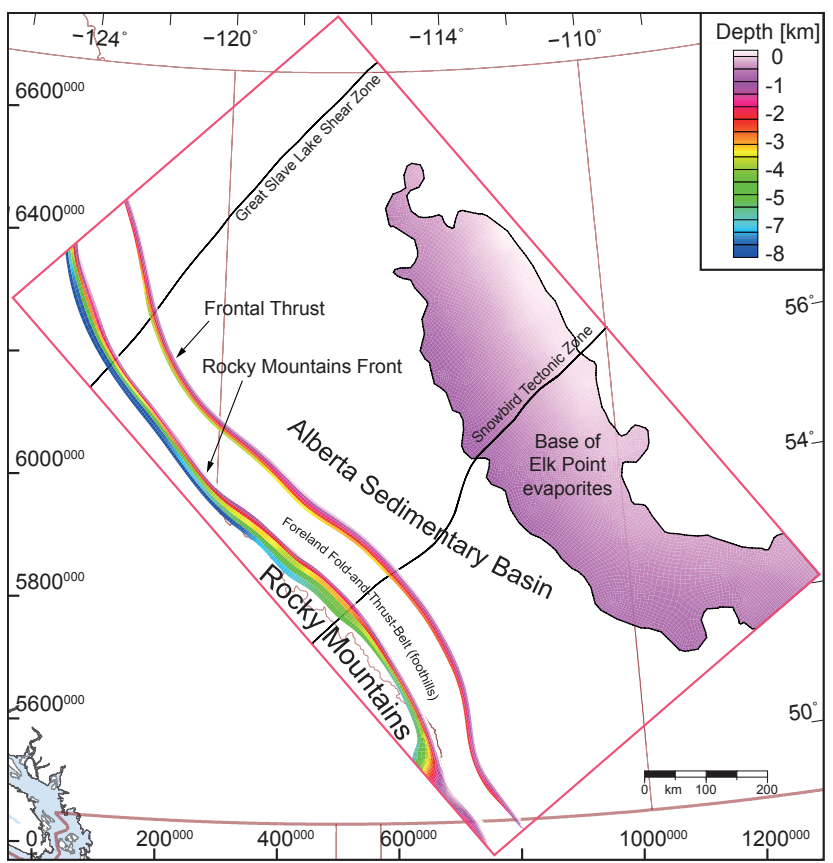

Figure 7. Upper crustal structures used in the model. The units above the basement are separated in the basin, the foothills and the Rocky Mountains. The basin also contains a thin rock salt layer from the Elk Point group. Within the basement, the Great Slave Lake Shear Zone and the Snowbird Tectonic Zone are incorporated. The map extent is indicated by geographical coordinates (top and right) and by UTM coordinates from zone 11 (left and bottom).

functions. The partial differential equation of the equilibrium of forces is solved numerically using the Abaqus ${ }^{\circledR} /$ Standard v.6.11 finite element software.

\subsection{Rock properties}

To calculate the stresses, Young's modulus $(E)$ and Poisson's ratio $(v)$ are the essential geomechanical material properties. The body forces of the rock units are represented by the density $(\rho)$. Mantle density below Alberta ranges from 3346 to $3366 \mathrm{~kg} \mathrm{~m}^{-3}$ according to White et al. (2005). For this model, a density of $3350 \mathrm{~kg} \mathrm{~m}^{-3}$ for the mantle is used (Table 1). The density of the Canadian Shield ranges from 2640 to $2830 \mathrm{~kg} \mathrm{~m}^{-3}$ (White et al., 2005), with this model using a value of $2800 \mathrm{~kg} \mathrm{~m}^{-3}$. Young's modulus and Poisson's ratio of the basement are calculated based on the $V_{p}$ and $V_{s}$ data from northern Alberta (Dalton et al., 2011). The dynamic Young's modulus and Poisson's ratio (0.21-0.22) are calculated according to Mavko et al. (2009). Based on the dynamic Young's modulus, the static Young's modulus is calculated according to King (1983) and Wang et al. (2000), with a range of $1.02 \times 10^{10}$ to $8.56 \times 10^{10} \mathrm{~Pa}$. In the model, 0.21 and $7.0 \times 10^{10}$ are used as Poisson's ratio and Young's modulus respectively for the basement, which is in agreement with data from Turcotte and Schubert (2002). Most
Phanerozoic sediments overlying the basement, including the foothills and the Rocky Mountains, are mainly clastic sediments (e.g. sandstone or shale) and limestone, with the exception of the separated evaporates. These material properties are estimated based on Fossen (2010), Okrusch and Matthes (2005) and Turcotte and Schubert (2002); see Table 1 .

\subsection{Initial stress state}

Deformation of the model due to gravity-driven subsidence is not desired. Therefore, an initial stress state of the model is derived, which is in equilibrium with the body forces (gravity). For the initial stress state, uniaxial strain conditions (Eq. 2) or lithostatic stress conditions for greater depths (Heim, 1878, Eq. 3) are often assumed.

$$
\begin{aligned}
& S_{\text {Hmean }}=\frac{S_{\text {Hmax }}+S_{\mathrm{hmin}}}{2}=S_{\mathrm{V}}\left(\frac{v}{1-v}\right) \\
& S_{\mathrm{Hmax}}=S_{\mathrm{hmin}}=S_{\mathrm{V}} \\
& k=\frac{S_{\text {Hmean }}}{S_{\mathrm{V}}}=\frac{S_{\mathrm{Hmax}}+S_{\mathrm{hmin}}}{2 S_{\mathrm{V}}} .
\end{aligned}
$$

Using uniaxial strain conditions $(k=1 / 3$ when $v$ is 0.25 , Eq. 2) or lithostatic conditions ( $k=1$, Eq. 3 ), the stress ratio $k$ (Eq. 4) is constant for both, when plotting vs. depth, but when $k$ is plotted vs. depth, based on in situ data, the discrepancy is obvious (e.g. Brown and Hoek, 1978; Gay, 1975, Fig. 9a). Visible are increasing $k$ values close to the surface. Thus, assuming lithostatic or uniaxial conditions is apparently insufficient for appropriate initial stress conditions.

Sheorey (1994) provides a simple spherical earth model for tectonically calm regions with no significant lateral density and strength contrasts. In this model, $k$ is a function (Eq. 5) of Young's modulus ( $E$ in GPa) and depth ( $z$ in $\mathrm{m}$ ). This was confirmed by later published in situ stress magnitudes from the KTB borehole (Brudy et al., 1997, see Fig. 9a).

$k=0.25+7 E\left(0.001+\frac{1}{z}\right)$

When the model is embedded in an extended model with inclined edges, it is possible to find a fit of the $k$ values vs. depth from the model. This is in comparison to a synthetic depth distribution, based on the Sheorey equation (Eq. 5). This technique has so far been used only occasionally (Buchmann and Connolly, 2007; Hergert and Heidbach, 2011). By generating the initial stress model, settlement due to the gravitational load occurs. Using the initial stress condition in the stress model, settlement in the model $(<1 \mathrm{~m})$ can be neglected in relation to the model size.

For comparison, the calculated $k$ ratio, Eq. (5) from Sheorey (1994), and the initial $k$ ratio from the model of Alberta, are plotted vs. depth. Material properties are adjusted for the 
Table 1. Material properties of the Alberta model.

\begin{tabular}{lccc}
\hline Lithology & $\begin{array}{c}\text { Density } \\
\left(\mathrm{kg} \mathrm{m}^{-3}\right)\end{array}$ & $\begin{array}{c}\text { Young's } \\
\text { modulus }(\mathrm{Pa})\end{array}$ & $\begin{array}{c}\text { Poisson's } \\
\text { ratio }\end{array}$ \\
\hline Sediments & $2200^{\mathrm{a}}$ & $6.0 \times 10^{10 \mathrm{~b}}$ & $0.15^{\mathrm{b}}$ \\
Rock salt & $2100^{\mathrm{c}}$ & $4.0 \times 10^{10 \mathrm{~d}}$ & $0.38^{\mathrm{d}}$ \\
Foothills & $2400^{\mathrm{b}}$ & $6.0 \times 10^{10 \mathrm{~b}}$ & $0.20^{\mathrm{b}}$ \\
Rocky Mtns. & $2500^{\mathrm{b}}$ & $6.0 \times 10^{10 \mathrm{~b}}$ & $0.20^{\mathrm{b}}$ \\
Basement & $2800^{\mathrm{e}}$ & $7.0 \times 10^{10 \mathrm{f}}$ & $0.21^{\mathrm{f}}$ \\
Mantle & $3350^{\mathrm{e}}$ & $1.5 \times 10^{11 \mathrm{~b}}$ & $0.25^{\mathrm{b}}$ \\
\hline
\end{tabular}

a Best fit (tested during calibration)

b Estimated based on Turcotte and Schubert (2002).

${ }^{c}$ Okrusch and Matthes (2005)

d Fossen (2010)

e White et al. (2005)

${ }^{\mathrm{f}}$ Calculated based on Dalton et al. (2011).

initial model only until good agreement is obtained. Exemplarily, two of them are plotted for illustration (Fig. 9b and c). From a purely technical point of view, the initial stress conditions were determined after calibration of the used sediment density.

\subsection{Boundary conditions}

Henton et al. (2006) and Mazzotti et al. (2011) showed that surface strain measured by GPS indicates strain rates are below the measurement error within Alberta and the Rocky Mountains. More to the west, in the Intramontane Belt, the values are also very low, yet in the coastal cordilleras, rates of about $10-15 \mathrm{~mm} \mathrm{yr}^{-1}$ in the northeasterly direction with respect to stable North America are observed. The North American Eulerian rotation pole is located southwest of Ecuador, resulting in an anticlockwise rotation of about $20 \mathrm{~mm} \mathrm{yr}^{-1}$ in the southwesterly direction in Alberta (Henton et al., 2006). Flesch et al. (2007) found that (deviatoric) stresses associated with the accommodation of relative plate motion are of the same order of magnitude as buoyancy forces (gravitational potential energy - GPE). The orientation of observed North American rotation, shortening in the Canadian Cordillera (Henton et al., 2006; Mazzotti et al., 2011), and GPE gradient orientation (Flesch et al., 2007) correspond to the observed average $S_{\mathrm{Hmax}}$ azimuths in Alberta (see the rose diagram in Fig. 4).

As the model edges are parallel and perpendicular, respectively, to the observed plate motion, GPE and horizontal stress azimuth, displacement at the model boundaries will be applied orthogonally to the side walls of the model box. Horizontal and vertical motion is allowed along the side walls (Fig. 4). The applied amount and orientation of push (towards the northeast) and pull (towards the southeast) along the model will be tested during the calibration phase of the model. The bottom of the model is fixed in the $z$ direction; lateral motion within the extent of the model box is allowed.

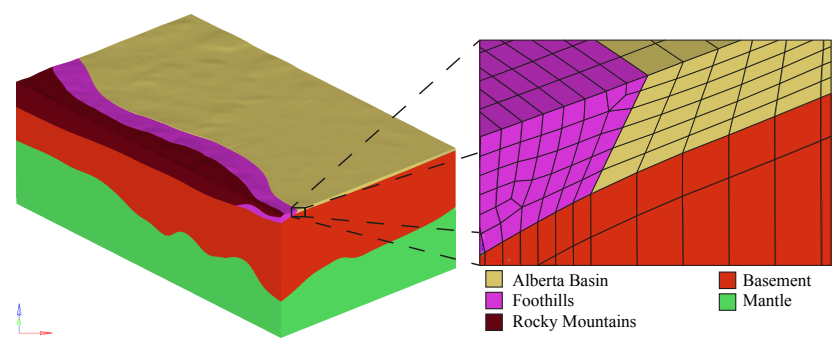

Figure 8. 3-D view of the Alberta model, view from south to north - rock units are indicated by colours. A small cut-out is zoomed in to see the mesh in detail. The vertical exaggeration is 5 times.

\section{In situ stress}

This section presents a short introduction to the terminology used for the stress data during the model calibration procedure.

\subsection{Orientation and magnitudes of stresses in sedimentary basins}

The 3-D stress in rock $(\sigma)$ is described with a second-order tensor. By choosing an principal coordinate system, the stress tensor $\left(\sigma_{i j}\right)$

$\boldsymbol{\sigma}_{\boldsymbol{i} \boldsymbol{j}}=\left(\begin{array}{lll}\sigma_{11} & \sigma_{12} & \sigma_{13} \\ \sigma_{21} & \sigma_{22} & \sigma_{23} \\ \sigma_{31} & \sigma_{32} & \sigma_{33}\end{array}\right)$ or $\left(\begin{array}{lll}\sigma_{x x} & \sigma_{x y} & \sigma_{x z} \\ \sigma_{y x} & \sigma_{y y} & \sigma_{y z} \\ \sigma_{z x} & \sigma_{z y} & \sigma_{z z}\end{array}\right)$,

can be expressed with the three principal stresses:

$\hat{\boldsymbol{\sigma}}_{i j}=\left(\begin{array}{ccc}\sigma_{1} & 0 & 0 \\ 0 & \sigma_{2} & 0 \\ 0 & 0 & \sigma_{3}\end{array}\right)$.

These act normally to the principal planes and are the following: $\sigma_{1}>\sigma_{2}>\sigma_{3}$, in the order of magnitude. As the earth's surface is a free surface, and sedimentary basins are roughly flat at the top, it is often assumed that the vertical stress $\left(S_{\mathrm{V}}\right)$ is a principal stress. With this assumption, the minimum horizontal stress $\left(S_{\mathrm{hmin}}\right)$ and the maximum horizontal stress $\left(S_{\mathrm{Hmax}}\right)$ (e.g. Jaeger et al., 2009; McGarr and Gay, 1978; Schmitt et al., 2012) are also principal stresses that are orthogonal to each other (Fig. 10). Their relative magnitudes determine the stress regime (Anderson, 1951, cited in Kanamori and Brodsky, 2004):

$$
\begin{aligned}
& \text { - normal faulting: } S_{\mathrm{V}}>S_{\mathrm{H} \max }>S_{\mathrm{hmin}} \\
& \text { - strike slip: } S_{\mathrm{H} \max }>S_{\mathrm{V}}>S_{\mathrm{hmin}} \\
& \text { - reverse faulting: } S_{\mathrm{H} \max }>S_{\mathrm{hmin}}>S_{\mathrm{V}} \text {. }
\end{aligned}
$$

More details can be found in Amadei and Stephansson (1997), Jaeger et al. (2009), Schmitt et al. (2012), Zang and Stephansson (2010) and Zoback (2007). 

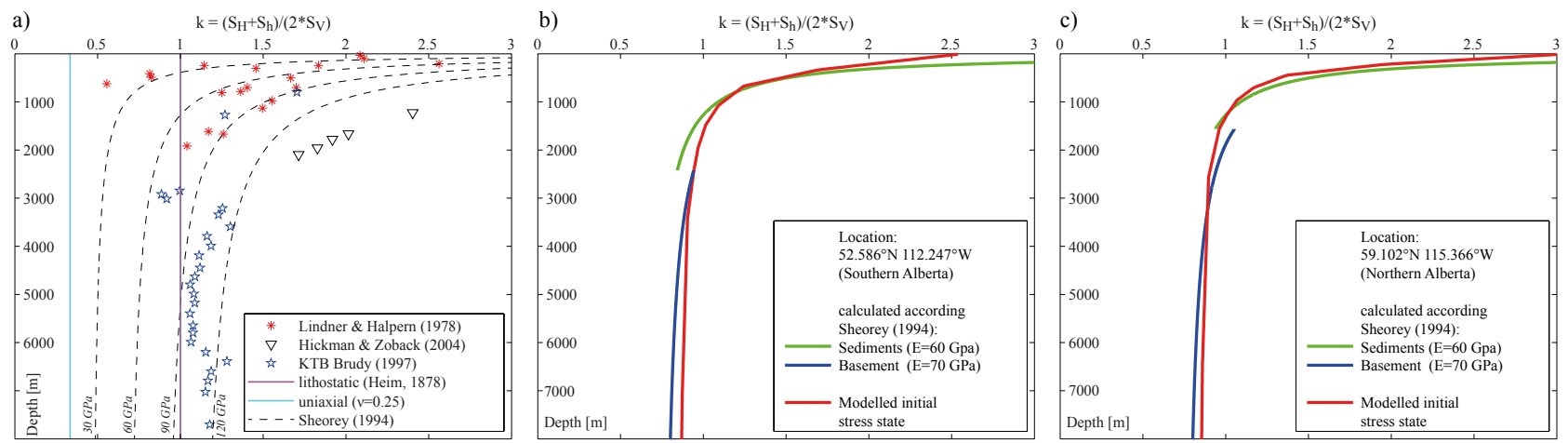

Figure 9. (a) Compilation of $k$ ratios from North America (Lindner and Halpern, 1978), the SAFOD pilot hole (Hickman and Zoback, 2004) and from the KTB (Brudy et al., 1997). Theoretical $k$ ratios based on the assumption of lithostatic load at greater depths (Heim, 1878, $k=1$ ), uniaxial strain conditions (Eq. 2) and the distribution according to Sheorey (1994, Eq. 5) for Young's modulus $E=30,60,90$ and $120 \mathrm{GPa}$ are plotted. (b) and (c) Depth profile of the initial and calculated $k$ values for two test sites within the model. Blue and green lines indicate calculated $k$ profiles based on Sheorey (1994, Eq. 5) and the associated Young's modulus. The red line indicates the $k$ profiles from the model with the initial stress state.

\subsection{Contemporary stress field in the Alberta Basin}

The present-day stress field in Alberta has been the subject of several studies. It started with Bell and Gough (1979) recognizing in the Alberta Basin that borehole breakouts are an indicator of crustal stress orientation (Fig. 10). They found that the $S_{\text {Hmax }}$ azimuth is uniformly oriented southwest to northeast in substantial parts of the Alberta Basin (Fig. 11). This observed orientation is perpendicular to the Rocky Mountain trench, which was confirmed by Adams and Bell (1991), Bell and Gough (1981), Bell et al. (1994), Fordjor et al. (1983) and recently by Reiter et al. (2014). Orientation data are derived from a large variety of rock types, depths, and different indicators. These are borehole breakouts at a depth range of 113-5485 m (e.g. Bell et al., 1994), geological indicators (Bell, 1985), and drilling-induced tensile fractures (Fordjor et al., 1983), and seismological studies in the Canadian Cordillera (Ristau et al., 2007) confirmed the overall orientation pattern (Fordjor et al., 1983). Only an anticlockwise rotation of about $10-20^{\circ}$ is observed in northern Alberta over the Peace River Arch.

The same homogeneous stress orientation is observed over wide areas of the North American plate (Bell and Gough, 1979; Adams and Bell, 1991; Fordjor et al., 1983; Gough et al., 1983; Reiter et al., 2014; Sbar and Sykes, 1973; Zoback and Zoback, 1980), which indicates that southwestto-northeast stress orientation is present over the whole lithosphere rather than sediments only (Fordjor et al., 1983). This implies also that the sediments are attached to the basement (Bell, 1996b). The $S_{\mathrm{Hmax}}$ orientation is at a right angle to the Rocky Mountains fold axis. Therefore, the stress field responsible for thrust faulting in Mesozoic time is still present (Bell and Gough, 1979). The driving force of the observed stress pattern is plate tectonics, either by drag resistance of the lithosphere sliding over asthenosphere (Bell and McLel-

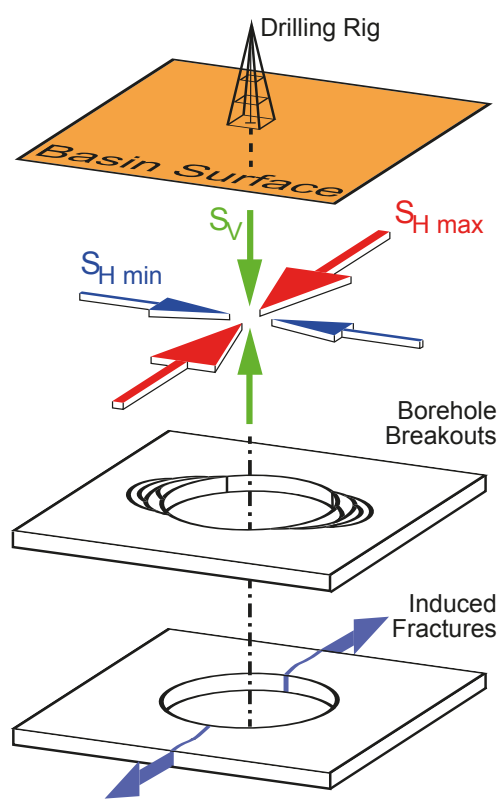

Figure 10. General assumption of stresses in sedimentary basins: the vertical stress $\left(S_{\mathrm{V}}\right)$ is a principal stress, thus perpendicular to the minimum and maximum horizontal stress $\left(S_{\mathrm{hmin}}\right.$ and $\left.S_{\mathrm{Hmax}}\right)$. Borehole breakouts occur in orientation of the $S_{\mathrm{hmin}}$, and induced tensile fractures occur in orientation of $S_{\mathrm{Hmax}}$.

lan, 1995; Zoback and Zoback, 1980) or mantle convection propelling the lithosphere (Bell and Gough, 1979; Fordjor et al., 1983; Gough, 1984).

The depth gradients of $S_{\mathrm{V}}$ and $S_{\mathrm{hmin}}$ increase from the basin centre towards the foothills and the Rocky Mountains (Baranova et al., 1999; Bell, 1996b; Bell and Bachu, 2004; Bell and Grasby, 2012). This trend coincides with higher organic maturity (England and Bustin, 1986; Nurkowski, 1984) and larger compaction (Bell and Bachu, 2004) in that 


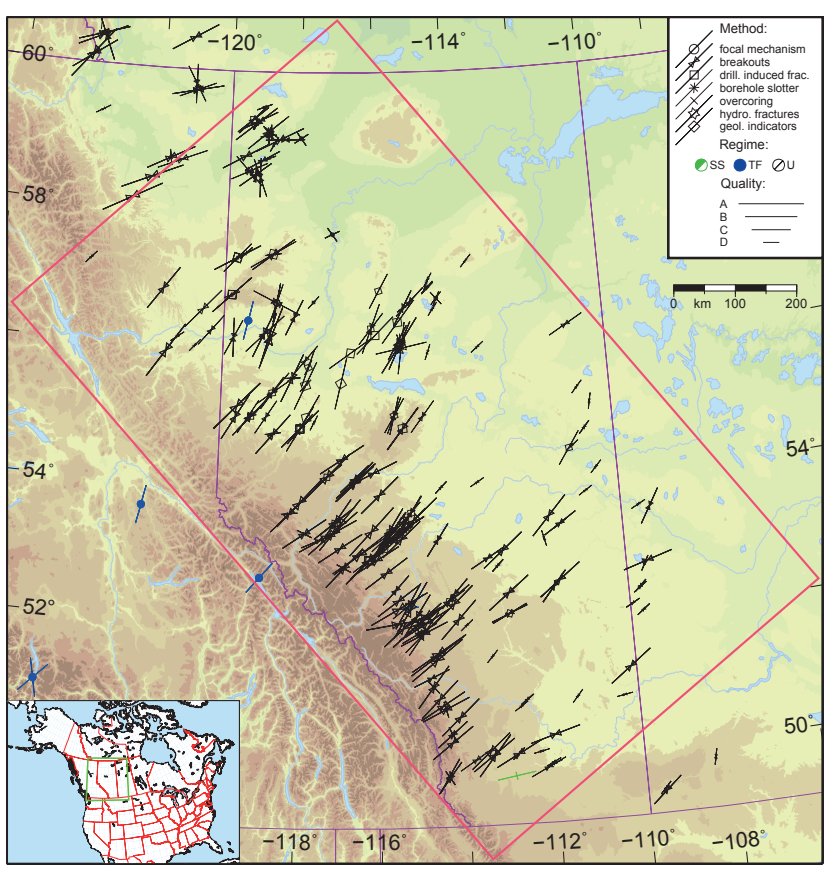

Figure 11. Crustal stress map of Alberta. Lines represent orientations of maximum horizontal compressional stress $S_{\mathrm{Hmax}}$; line length is proportional to the data quality. Colours indicate stress regimes, with green for strike-slip faulting (SS), blue for thrust faulting (TF), and black for unknown regime (U). In summary, there are $321 S_{\text {Hmax }}$ azimuth data available within the modelled region. Data are from the latest update of the Canadian stress map (Reiter et al., 2014).

direction, which is related to the depth of present and past burial. The maximum erosion of basin sediments is by about $1400 \mathrm{~m}$ (Woodland and Bell, 1989), uplift occurring since the mid-Cenozoic time, mainly in the foothills (Bell and McLellan, 1995).

The stress regime in the basin sediments changes from thrust faulting in the foothills to strike slip within the basin, up to a normal faulting regime further east in Saskatchewan (Bell and Gough, 1979; Bell et al., 1994; Bell and McLellan, 1995; Bell and Bachu, 2003; Bell and Grasby, 2012; Woodland and Bell, 1989). A similar change from surface to depth is observed: from thrust faulting at $<350-600 \mathrm{~m}$ in depth, strike slip in a depth range of about $500-2500 \mathrm{~m}$, down to normal faulting at greater depths $>2500 \mathrm{~m}$ (Bell and Babcock, 1986; Fordjor et al., 1983; Jenkins and Kirkpatrick, 1979). There is also a varying $S_{\mathrm{hmin}}$ gradient discussed (Bachu et al., 2008; Bell and Grasby, 2012; Hawkes et al., 2005), but this is may be due to different measurement methods (Bell et al., 1994) or man-made stress changes. The $S_{\text {Hmax }} / S_{\text {hmin }}$ ratio in the Alberta Basin is about 1.3-1.6 (Fordjor et al., 1983).

Man-made stress perturbation due to hydrocarbon production or acid gas injections (e.g. Bachu et al., 2008; Bell and Grasby, 2012; Woodland and Bell, 1989) reduces or in- creases reservoir fluid pressure respectively, but has likely only local effects (e.g. Altmann et al., 2010). Furthermore, Baranova et al. (1999) found a strong correlation between rates of gas production and the number of seismic events, which is reasonable because production lead to decrease of $S_{\mathrm{V}}$ and increase of $S_{\mathrm{Hmax}}-$ consequentially increasing differential stresses. The stress change due to the gas extraction point to a regime, which favours thrust faulting (Baranova et al., 1999). Hydraulic fractures applied for hydrocarbon industry or for enhanced geothermal systems deeper than $350 \mathrm{~m}$ will open parallel to southwest- to northeastoriented $S_{\mathrm{Hmax}}$ orientations, except that in the Peace River Arch, they will tend to south-soutwest to north-northeast (Bell et al., 1994; Bell and Grasby, 2012). Close to the Rocky Mountain foothills, northwest- to southeast-oriented hydraulic fractures are possible parallel to the thrust planes and the fold axes (Bell and Babcock, 1986). However, horizontal wells e.g. for EGS should be designed parallel to the $S_{\mathrm{hmin}}$ orientation (Bell and Grasby, 2012).

\subsection{In situ stress data}

\subsubsection{Vertical stress $\left(S_{\mathrm{V}}\right)$}

The vertical stress $\left(S_{\mathrm{V}}\right)$ is the overburden load, which is estimated using density logs (e.g. Gardner and Dumanoir, 1980) in a well:

$S_{\mathrm{V}}=\int_{0}^{z} \rho(z) g \mathrm{~d} z \approx \bar{\rho} g z$.

For the Alberta model region $981 S_{\mathrm{V}}$ magnitude data sets are available (provided by the AGS), these are indicated by black points in Fig. 12. $S_{\mathrm{V}}$ magnitude data vary only slightly, even in greater depths, the lateral variation is less than $5 \mathrm{MPa}$.

\subsubsection{Orientation of maximum horizontal stress $\left(S_{\mathrm{Hmax}}\right)$}

The orientation of $S_{\mathrm{Hmax}}$ is indicated by borehole breakouts, focal mechanisms, hydraulic fracturing, overcoring, and drilling-induced fractured and geological indicators (for an overview, see Bell, 1996a; Ljunggren et al., 2003; Schmitt et al., 2012; Zang and Stephansson, 2010; Zoback et al., 2003). $321 S_{\mathrm{Hmax}}$ azimuth data sets are available for the modelled region in Alberta; these are indicated in Fig. 11, based on the latest update of the Canadian stress database (Reiter et al., 2014).

\subsubsection{Magnitude of minimum horizontal stress $\left(S_{\mathrm{hmin}}\right)$}

The $S_{\mathrm{hmin}}$ magnitudes are measured by hydraulic fracturing or the similar leak-off test. During hydraulic fracturing (Bell, 1996a; Haimson and Cornet, 2003; Hubbert and Willis, 1957; Zoback et al., 2003) and leak-off tests (e.g. Li et al., 2009; White et al., 2002; Zhou, 1997), the down-hole pressure is increased up to pressure loss due to fluid leakage in the 


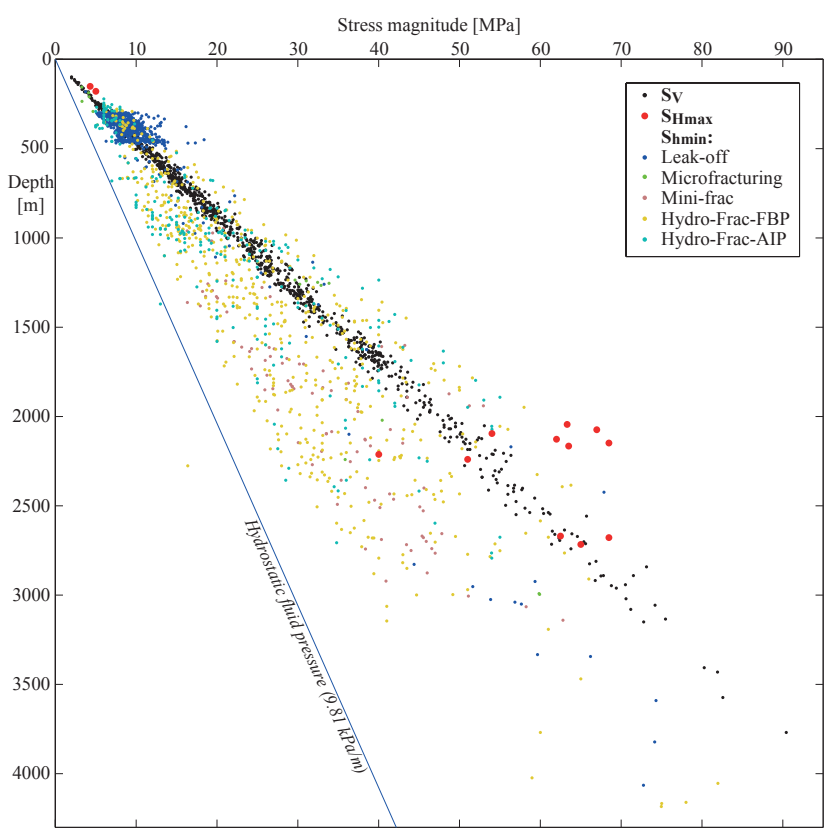

Figure 12. Depth plot of the in situ stress magnitudes. These are $981 S_{\mathrm{V}}$ magnitude data (black), $1720 S_{\mathrm{hmin}}$ magnitudes (several colours), and 2 measured as well as 11 calculated $S_{\text {Hmax }}$ magnitudes (highlighted red points). $S_{\mathrm{hmin}}$ data are colour coded depending on the test type, which is taken over from the original database.

rock mass. This happens, when the hydraulic fracture splits apart the surrounding rock perpendicular to the least principal stress $\left(\sigma_{3}\right)$, usually assumed to be $S_{\mathrm{hmin}}$ in sedimentary basins, and therefore the fracture opens in $S_{\mathrm{Hmax}}$ orientation (Fig. 10). The highest pressure is the fracture breakdown pressure (FBP, Haimson and Fairhurst, 1969), which is $S_{\mathrm{hmin}}+$ rock resistance up to failure. When the pressure at which the fracture closes or re-opens is less than $S_{\mathrm{V}}$, it is assumed that $S_{\mathrm{hmin}}$ is measured (Haimson and Fairhurst, 1969). The mini-frac test (e.g. McLellan, 1987; Woodland and Bell, 1989) and the micro-frac test (Gronseth and Kry, 1983) as hydro-fracturing methods estimate the closure pressure by opening and closing the fracture several times, but differs by the injected fluid volume.

The term "leak-off tests" is used variably, and can be distinguished by their aim into formation integrity tests (FIT), "classic" leak-off tests (LOT) and extended leak-off tests (XLOT) (White et al., 2002). The general method is similar, but differs in pumping cycles and the point at which the pumping is stopped. Usually, leak-off tests (LOT) are meant, which provide the upper limit of $S_{\mathrm{hmin}}$ and measure the fracture closure pressure (FCP) or the instantaneous shutin pressure (ISIP) (White et al., 2002). Extended leak-off tests (XLOT) allow measurement of the fracture re-opening pressure, like the original hydro-fracture tests.

For the model region, $1720 S_{\mathrm{hmin}}$ magnitudes data are available, provided by the AGS; see Fig. 12. These are 784 leak-off magnitude data and 936 magnitude data from hydraulic fracturing. The different hydraulic fracturing methods are 14 Micro-frac, 91 Mini-frac, 250 Hydro-Frac-AIP, and 581 Hydro-Frac-FBP data. The data scatter strongly, independently from the test method or lithology. Further detailed information about the measurements are not available; that would allow whether the data represents the undisturbed stress state or not. The scatter either reflects the spatial anisotropy of the in situ stress or that the data set is noisy, i.e. a mix of in situ stress information and data from areas with a disturbed stress field.

\subsubsection{Magnitude of maximum horizontal stress $\left(S_{\mathrm{Hmax}}\right)$}

The magnitude of $S_{\mathrm{Hmax}}$ is measured via the overcoring method (McGarr and Gay, 1978; Obert, 1962), which isolates a rock cylinder from the surrounding rock and measures the elastic relaxation of the rock cylinder. This is equivalent to the stress magnitude as well as the stress orientation, before removal of the surrounding rock. The drawbacks are the small quantity of inspected rock mass and the fact that the application is usually close to the surface. Furthermore, there are several methods used to calculate $S_{\mathrm{Hmax}}$, based on $S_{\mathrm{hmin}}$ magnitudes and known rock properties (e.g. Schmitt et al., 2012). For the model region, 11 calculated data (Bell et al., 1994) and 2 shallow measured data (overcoring from Kaiser et al., 1982) are available (see Fig. 12).

\section{Model calibrations}

\subsection{General comparison technique}

The 3-D geomechanical-numerical model (with the initial stress state) from Alberta will be calibrated in the following according to the work flow scheme (Fig. 1). Each type of in situ stress data will be used step by step to calibrate the model. We first use the $S_{\mathrm{V}}$ data to calibrate the density (technically, the initial stress state is found after this step); then, we use the $S_{\text {Hmax }}$ azimuth data to calibrate the orientation of applied displacement boundary conditions. Finally, the $S_{\mathrm{hmin}}$ and $S_{\mathrm{Hmax}}$ magnitudes are used to calibrate the magnitude of applied displacement boundary conditions, i.e. push and pull at the edges of the model box.

In each step, the modelled stress tensor is interpolated via inverse distance interpolation onto each point, where in situ stress data are available. The difference $(\Delta S)$ between measured stress $\left(S_{\text {Measured }}\right)$ and the modelled stress $\left(S_{\text {Model }}\right)$ is calculated in the following way:

$\Delta S=S_{\text {Measured }}-S_{\text {Model }}$,

which means that negative values indicate an overestimation by the model, and vice versa. A value close to zero indicates a good approximation of the in situ stresses by the model. To compare magnitude data independently of the range, the 
deviation is normalized by the modelled stress value:

$n \Delta S=\frac{S_{\text {Measured }}-S_{\text {Model }}}{S_{\text {Model }}}$.

To evaluate the differences between each in situ data set and the model as a whole, the median of $\Delta S(\widetilde{\Delta S})$ is calculated as a single value for each model. In the case of the best-fit model, the $\widetilde{\Delta S}$ shall be close to zero. To estimate the influence of outliers and the variation of the data, the mean $(\overline{\Delta S})$ and the standard deviation (SD) is also calculated. The linear correlation between the in situ data and the model data is represented by the Pearson product-moment correlation coefficient $(r)$, where $r=1$ indicates total positive correlation, $r=-1$ total negative correlation and $r=0$ no correlation.

The data sets are contaminated with unlikely in situ data; such data are often sorted out (e.g. Bell and Bachu, 2004; Bell and Grasby, 2012) for interpolation. As statistical tests are used in this study, data weed out is not required.

\subsection{Calibration of material density on $S_{\mathrm{V}}$ data}

The density of the sedimentary basin is calibrated based on $S_{\mathrm{V}}$ magnitudes $(n=981$, Fig. 12$)$; all other material properties are defined in Sect. 3.2. The overall density of the modelled basin sediments is tested with 2200, 2300 and $2400 \mathrm{~kg} \mathrm{~m}^{-3}$. According to Eq. (9), the difference between the measured and modelled $S_{\mathrm{V}}\left(\Delta S_{\mathrm{V}}\right)$, as well as the normalized $\Delta S_{\mathrm{V}}\left(n \Delta S_{\mathrm{V}}\right)$, are calculated:

$$
\begin{aligned}
& \Delta S_{\mathrm{V}}=S_{\mathrm{V} \text { Measured }}-S_{\mathrm{V} \text { Model }} . \\
& n \Delta S_{\mathrm{V}}=\frac{S_{\mathrm{V} \text { Measured }}-S_{\mathrm{V} \text { Model }}}{S_{\mathrm{V} \text { Model }}} .
\end{aligned}
$$

The model with a density of $2200 \mathrm{~kg} \mathrm{~m}^{-3}$ has a $\widetilde{\Delta S} \mathrm{~V}$ which is close to zero $(-0.09 \mathrm{MPa})$ and a $\overline{\Delta S}_{\mathrm{V}}$ of $0.28 \mathrm{MPa}$, which is also close to zero (Fig. 13). A standard deviation of $5.58 \mathrm{MPa}$ as well as the Gaussian distribution in the normalized histogram (Fig. 14a) indicate that there is no large data drift. The correlation coefficient of $r=0.935$ indicates a good fit.

\subsection{Calibration of the orientation of displacement boundary conditions based on $S_{\mathrm{Hmax}}$ azimuth data}

The $S_{\mathrm{Hmax}}$ orientation is controlled by the applied displacement boundary conditions. Within the model region, 321 $S_{\mathrm{Hmax}}$ orientation data are available. They are displayed together with the data aside of the model in the stress map from Alberta (Fig. 11). The observed stress pattern is quite homogeneous.

The displacement boundary conditions act orthogonally to the model margins, in a horizontal direction. Whereas shortening is applied in a northeasterly direction to the model, extension is applied in a southeasterly direction (Fig. 4). According to Eq. (9), the difference between the measured and

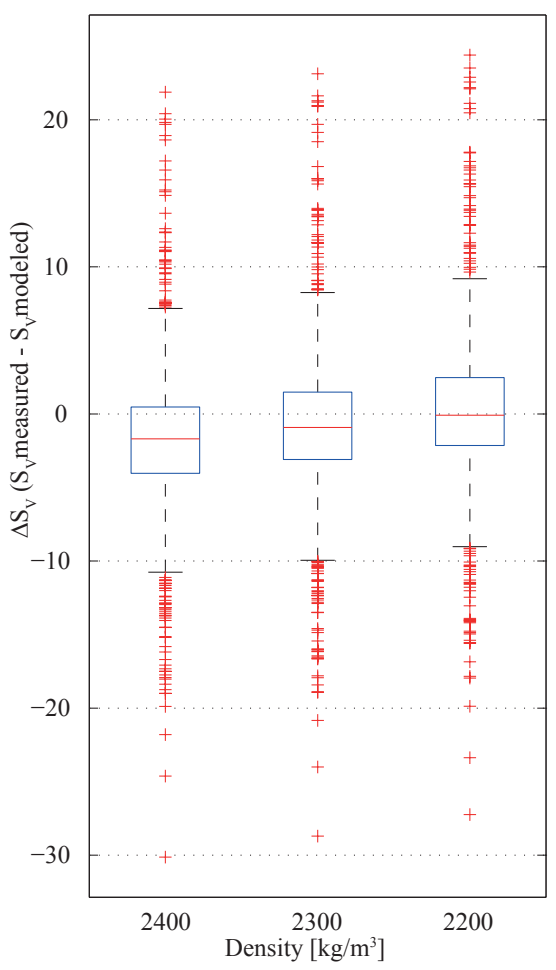

Figure 13. Boxplot of the varied density of the basin sediments plotted is the $\Delta S_{\mathrm{V}}$. The median $\Delta S_{\mathrm{V}}$ of the model with a density of $2200 \mathrm{~kg} \mathrm{~m}^{-3}$ is close to $0 \mathrm{MPa}$ and therefore the best-fit density to the available $S_{\mathrm{V}}$ data, in contrast to the models with a higher basin density, where $\Delta S_{\mathrm{V}}$ is negative (see Eq. 11).

modelled $S_{\mathrm{Hmax}}$ azimuth is calculated. Eq. (13) is expanded with two additional lines, due to the fact that $S_{\mathrm{Hmax}}$ orientation data are circular data $\left(0-180^{\circ}\right.$, and $\left.0^{\circ}=180^{\circ}\right)$, and therefore $\Delta S_{\mathrm{Hmax}}$ Azi have to range from $-90^{\circ}$ to $+90^{\circ}$ :

$$
\begin{aligned}
& \Delta S_{\text {Hmax Azi }}=S_{\text {Hmax Azi Meas }}-S_{\text {Hmax Azi Model }} \\
& \quad-90\left(\operatorname{sgn}\left(S_{\text {Hmax Azi Meas }}-S_{\text {Hmax Azi Model }}-90\right)\right. \\
& \left.\quad+\operatorname{sgn}\left(S_{\text {Hmax Azi Meas }}-S_{\text {Hmax Azi Model }}+90\right)\right) .
\end{aligned}
$$

The histogram of the $\Delta S_{\text {Hmax }}$ azimuths (Fig. 14b) displays a main cluster around zero with a $\widetilde{\Delta S}$ Hmax azimuth of $-3.44^{\circ}$. The main cluster ranges from $-40^{\circ}$ to $40^{\circ}$; a second (smaller) cluster ranges from $-50^{\circ}$ over $\pm 90^{\circ}$ to $60^{\circ}$, with a slight peak around $\pm 90^{\circ}$. This is exactly orthogonal to the main cluster and explains the large SD of $26.9^{\circ}$; the mean $\left(\overline{\Delta S}_{\mathrm{H} \max }=3.42^{\circ}\right)$ is similar to the median. The best-fit orientation is found for a large range of push and pull magnitudes. Therefore, different oriented boundary conditions are not further tested. 

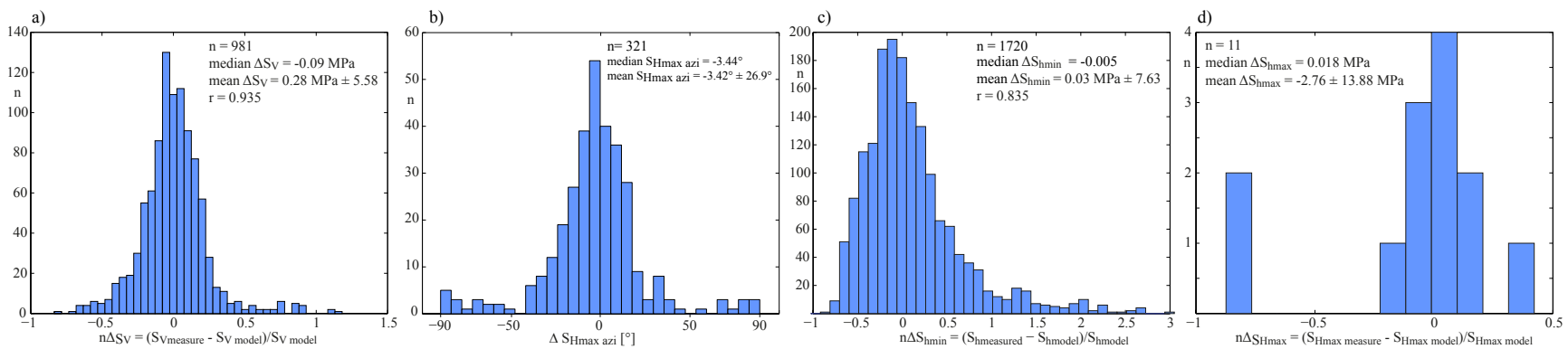

Figure 14. Distribution plots of the best-fit model, the number of data, the median, the mean, the standard deviation (SD) and the Pearson product-moment correlation coefficient ( $r$ ) for the most $n \Delta S$ or $\Delta S$ are indicated in the histograms. (a) The histogram of the normalized $\Delta S_{\mathrm{V}}$ displays a nice Gaussian distribution. (b) The histogram of the $\Delta S_{\mathrm{Hmax}}$ azimuth data displays one major cluster around zero, with a range from -40 to $40^{\circ}$; a second smaller cluster ranges in orientation between $-50^{\circ}$ over $\pm 90^{\circ}$ to $60^{\circ}$, with the highest peak by about $\pm 90^{\circ}$. (c) The normalized $\Delta S_{\mathrm{hmin}}$ magnitudes display a positive screwed distribution. (d) The normalized $\Delta S_{\mathrm{Hmax}}$ magnitude histogram for the 13 available data displays two negative outliers (the two shallow (overcoring) data). However, the 11 calculated data are arranged around zero.

\subsection{Calibration of the magnitude of displacement boundary conditions by $S_{\mathrm{hmin}}$ and $S_{\mathrm{Hmax}}$ magnitude data}

The $S_{\mathrm{hmin}}(n=1720)$ and $S_{\mathrm{Hmax}}(n=13: 2$ measured and 11 calculated) magnitude data (Fig. 12) are used to calibrate the magnitude of applied push and pull along the model edges (Fig. 4). The aim is a model, which mimics the $S_{\mathrm{hmin}}$ and $S_{\text {Hmax }}$ in situ magnitude data quite well. Several scenarios with different amount of push and pull are calculated, to estimate the range of push and pull, close to the best-fit model. In the following we focus in only four scenarios with a different amount of push and pull (Table 2). According to Eqs. (9) and (10) the difference between the measured and modelled $S_{\mathrm{hmin}}$ and $S_{\mathrm{Hmax}}$ magnitudes are calculated as well as the normalized difference.

$$
\begin{aligned}
& \Delta S_{\mathrm{hmin}}=S_{\mathrm{hmin} \text { Measured }}-S_{\mathrm{hmin} \text { Model }}, \\
& \Delta S_{\mathrm{H} \max }=S_{\mathrm{Hmax} \text { Measured }}-S_{\mathrm{Hmax} \text { Model }}, \\
& n \Delta S_{\mathrm{hmin}}=\frac{S_{\mathrm{hmin} \text { Measured }}-S_{\mathrm{hmin} \text { Model }}}{S_{\mathrm{hmin} \text { Model }}}, \\
& n \Delta S_{\mathrm{Hmax}}=\frac{S_{\mathrm{Hmax} \text { Measured }}-S_{\mathrm{Hmax} \text { Model }}}{S_{\text {Hmax Model }}} .
\end{aligned}
$$

The calculated $\widetilde{\Delta S} \mathrm{hmin}$ and $\widetilde{\Delta S} \mathrm{Hmax}$ of four model runs (Table 2) are plotted in the push vs. pull diagram (Fig. 15a and b). To highlight the linear dependency between push and pull in an elastic model, colour coded isolines are plotted. Each model along the light blue line (Fig. 15a) would derive a model, which fits well with the in situ $S_{\mathrm{hmin}}$ data. The same stands for the light blue line in Figs. 15b and $S_{\mathrm{Hmax}}$ data. As the determination of the best-fit model is intended, the intersection of both light blue lines from Fig. 15a and $\mathrm{b}$ would derive such a model. This is done with a bivariate linear regression based on the spatial distribution of the $\widetilde{\Delta S}$ hmin and $\widetilde{\Delta S}$ Hmax (Fig. 15c). This method
Table 2. Overview of major push-and-pull experiments. The orientation of the displacement boundary condition is indicated in Fig. 4. Four test scenarios with different push and pull magnitudes are displayed, same as in Fig. 15a and b. The displacement boundary conditions for the best-fit model (last line) are calculated based on bivariate linear regression; see text.

\begin{tabular}{crrrr}
\hline \multirow{3}{*}{ Models } & $\begin{array}{r}\text { Push } \\
\text { from SW } \\
(\mathrm{m})\end{array}$ & $\begin{array}{r}\text { Pull } \\
\text { to SE } \\
(\mathrm{m})\end{array}$ & $\begin{array}{r}\text { cmedian } \\
\Delta S_{\text {hmin }} \\
(\mathrm{MPa})\end{array}$ & $\begin{array}{r}\text { cmedian } \\
\Delta S_{\text {Hmax }} \\
(\mathrm{MPa})\end{array}$ \\
\hline \multirow{3}{*}{ Test } & 0.00 & 150.00 & -1.120 & 7.246 \\
scenarios & 200.00 & 100.00 & -6.424 & -10.800 \\
& -50.00 & -250.00 & 1.264 & -9.561 \\
& -280.00 & 6.273 & 12.705 \\
\hline Best fit & 86.24 & 194.52 & -0.005 & 0.018 \\
\hline
\end{tabular}

provides the following equations, which describes the zero isoline (light blue line) as a linear function. These are for median $\Delta S_{\mathrm{hmin}}=0$ :

$y=-0.2709 \cdot x-171.1586$,

and for the $\widetilde{\Delta S}_{\mathrm{Hmax}}$ zero isoline:

$y=-10.6642 \cdot x+725.1380$.

By equalizing Eqs. (18) and (19),

$x=\frac{725.1380+171.1586}{10.6642-0.2709}$,

the best-fit model has a push from southwest of $86.24 \mathrm{~m}$ and a pull in the southeasterly direction of $194.52 \mathrm{~m}$ (Table 2, last line).

The median values $\left(\widetilde{\Delta S}_{\mathrm{hmin}}=-0.005\right.$ and $\left.\widetilde{\Delta S}{ }_{\text {Hmax }}=0.018\right)$ fits quite well, the same stands for 

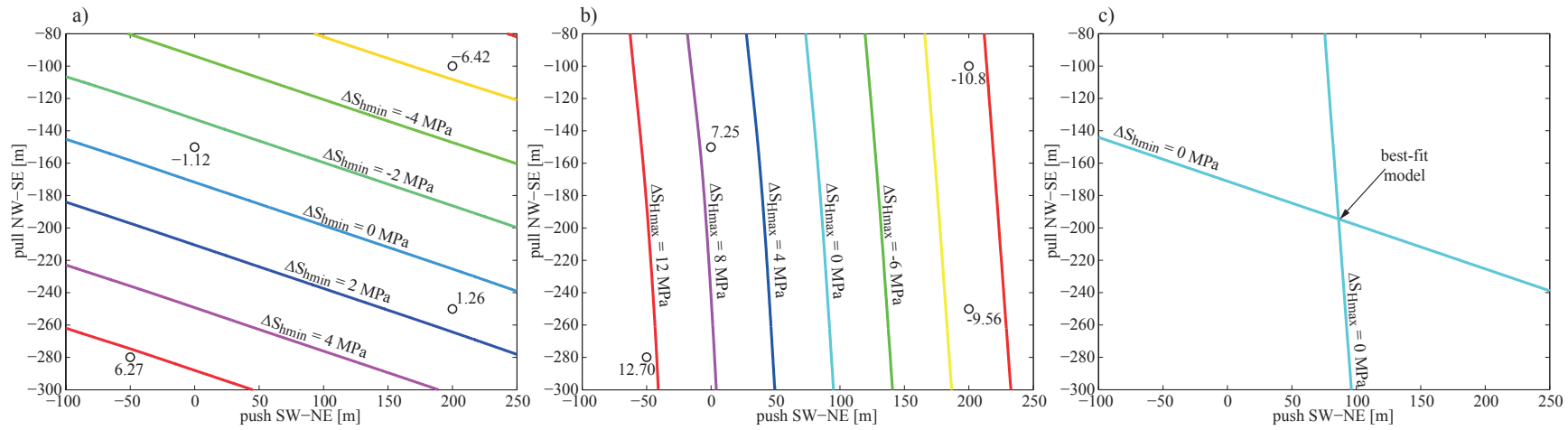

Figure 15. Plot of four models with different shortening or extension at the model boundary; see Table 2 for details. (a) and (b): the median $S_{\mathrm{hmin}}$ and the median $S_{\mathrm{Hmax}}$ are plotted depending on the northwest to southeast extension (pull) and the southwest to northeast shortening (push). The isolines of the median $\Delta S_{\mathrm{hmin}}$ and $\Delta S_{\mathrm{H} \max }$ are colour coded. (c) The isolines where the median $\Delta S_{\mathrm{hmin}}$ and $\Delta S_{\mathrm{Hmax}}$ are zero are plotted alone. The intersection of both isolines indicated the push-pull values where the best-fit model can be found.

the mean values $\left(\overline{\Delta S}_{\mathrm{hmin}}=0.03\right.$ and $\left.\overline{\Delta S}_{\mathrm{Hmax}}=-2.76\right)$. The distribution of the normalized $S_{\mathrm{hmin}}$ (Fig. 14c) displays a positive screwed distribution. The correlation coefficient of the in situ $S_{\mathrm{hmin}}$ magnitude data and the modelled $S_{\mathrm{hmin}}$ is $r=0.835$. The normalized best-fit of $S_{\mathrm{Hmax}}$ (Fig. 14d) displays two outliers; these are the only two measured $S_{\mathrm{Hmax}}$ magnitudes, measured at a depth of $152 \mathrm{~m}$.

\section{Discussions}

\subsection{Workflow and calibration}

The general workflow of model calibration (Fig. 1) is similar to other studies on numerical stress field modelling (e.g. Buchmann and Connolly, 2007; Fischer and Henk, 2013; Heidbach et al., 2013; Hergert and Heidbach, 2011). However, in contrast to former studies, the number of in situ stress data from the Alberta Basin allows a statistical comparison with the model results.

\subsection{1 $S_{V}$ calibration}

Given the large model size $(1200 \mathrm{~km} \times 700 \mathrm{~km} \times 80 \mathrm{~km})$, the Alberta Basin infill is considered to be one material type only, except for the Elk Point evaporates. The available data set of $981 S_{\mathrm{V}}$ magnitude data points (Fig. 12) could be used via linear regression to calculate the overall density of the sedimentary basin, but to incorporate the (minor) lateral effects of topography, the overall density is determined in the calibration process. Plotting the distribution of the normalized deviation $\left(n \Delta S_{\mathrm{V}}\right)$ in histogram Fig. 14a demonstrates a Gaussian distribution, which implies there is no process affecting data drift. As data spreading does not depend on the vertical depth, a slightly higher lithological resolution with linearly increasing density into depth would most likely not deliver a much better data fit. This could be solved by incorporation of all stratigraphic units, which would go far beyond

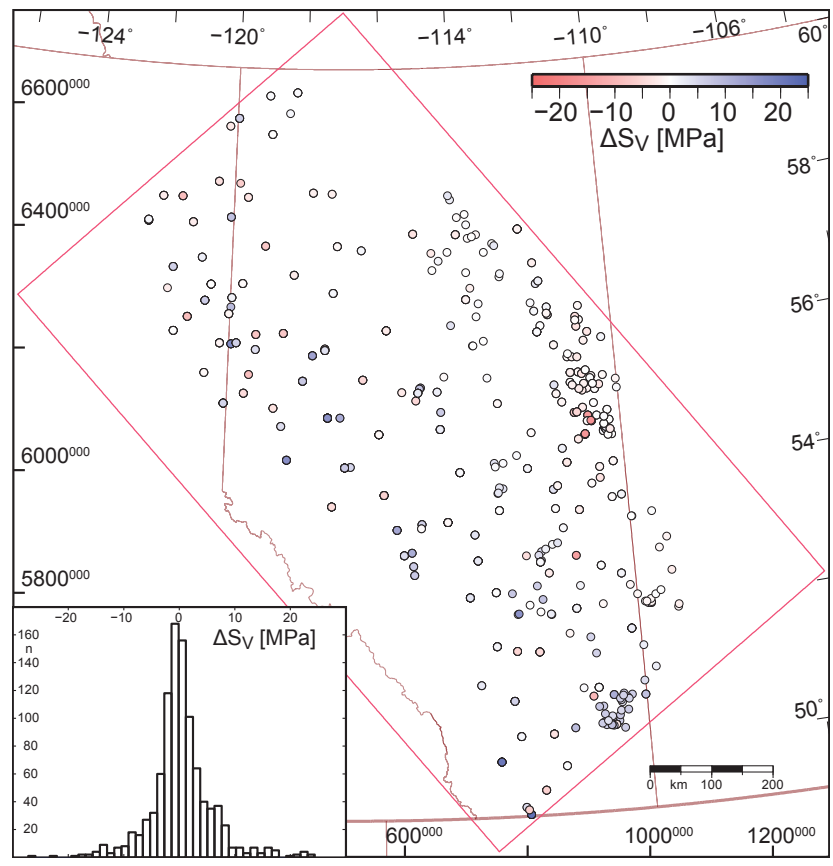

Figure 16. Spatial distribution of $\Delta S_{\mathrm{V}}$ differences are plotted colour coded. The map extent is indicated by geographical coordinates (top and right) and by UTM coordinates from zone 11 (left and bottom).

the goals of this study. The spatial plot of $\Delta S_{\mathrm{V}}$ (Fig. 16) shows that in situ $S_{\mathrm{V}}$ magnitudes are slightly higher close to the foothills. This is expected from former studies, showing $S_{\mathrm{V}}$ increases in the southwesterly direction (e.g. Bell and Bachu, 2004; Bell and Grasby, 2012). 


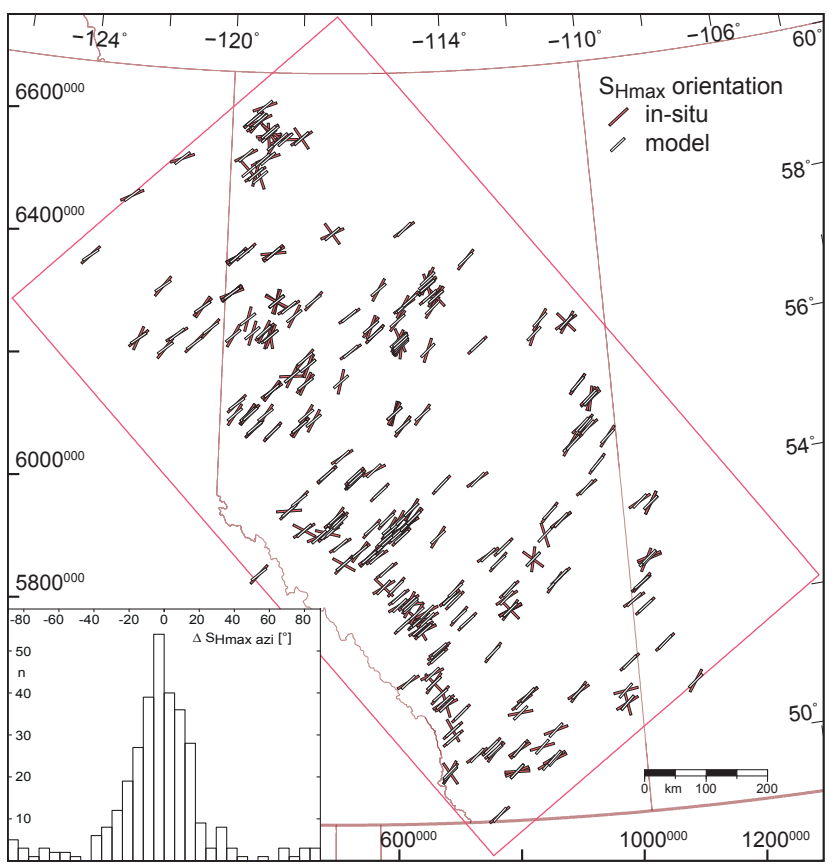

Figure 17. Spatial distribution of the modelled and in situ $S_{\mathrm{Hmax}}$ azimuth data. A good fit of the modelled data is reached, except for some suggested misinterpreted data (around $\pm 90^{\circ}$ ) and systematic rotations close to the Peace River Arch $\left(56^{\circ} \mathrm{N}, 118^{\circ} \mathrm{W}\right)$ and close to the Bow Island Arch $\left(50^{\circ} \mathrm{N}, 114^{\circ} \mathrm{W}\right)$. The map extent is indicated by geographical coordinates (top and right) and by UTM coordinates from zone 11 (left and bottom).

\subsubsection{Calibration of $S_{\mathrm{Hmax}}$ orientation}

The 321 data records of the $S_{\text {Hmax }}$ azimuth (Fig. 11) are used to test the orientation of the applied displacement boundary conditions. As long as a certain push to the northeast and a pull in the southeasterly direction are applied orthogonally to the model box (Fig. 4), a good fit of the stress orientation (Fig. 14b and 17) is achieved. No variation of the boundary conditions (orientation of push and pull) was necessary, due to the appropriately chosen model orientation.

The histogram of the $\Delta S_{\mathrm{Hmax}}$ azimuth (Fig. 14b) displays two data clusters. The larger cluster displays a normal distribution around zero, which is confirmed by a $\widetilde{\Delta S}_{\mathrm{Hmax}}$ azimuth of $-3.44^{\circ}$. A second data cluster is distributed around $\pm 90^{\circ}$, which explains the high SD of $26.9^{\circ}$. The second cluster with a deviation of around $\pm 90^{\circ}$ is the orientation of $S_{\text {hmin }}$ indicating that some of the used in situ $S_{\mathrm{Hmax}}$ azimuth data, are likely miss-interpreted $S_{\mathrm{hmin}}$ orientations. Such incorrect interpretations are sometimes observed in borehole breakout data (Brudy and Kjørholt, 2001; Barton and Moos, 2010); in such cases drilling induced tensile fractures, originated during drilling, are misinterpreted as borehole breakouts. Other reasons for orientation of data with right angles to the major population $\left(S_{\mathrm{hmin}}\right)$ are mud cake padding along caved zones and the collapse of pre- existing open fractures, again parallel to $S_{\mathrm{Hmax}}$ (Bell and Babcock, 1986; Bell and Grasby, 2012). Therefore, this second (smaller) cluster around $\pm 90^{\circ}$ rather confirms then disproves the good data fit by the model.

The alternative explanation would be a horizontal stress state close to isotropic. This would allow large stress rotation due to small local stress sources (Heidbach et al., 2007). However, from the provided data, this explanation can be ruled out, and the previously stated explanation is much more likely.

There are two areas in the modelled region, where a systematic difference of the $S_{\mathrm{Hmax}}$ azimuth between the in situ data and the model is visible (Fig. 17). These are the western Peace River Arch $\left(56^{\circ} \mathrm{N}, 118^{\circ} \mathrm{W}\right)$ and the Sweetgrass Arch in the very south, close to the southern Bow Island Arch $\left(50^{\circ} \mathrm{N}, 114^{\circ} \mathrm{W}\right)$. In the Peace River Arch, in situ $S_{\mathrm{Hmax}}$ is rotated by about $20-30^{\circ}$ anticlockwise (Bell et al., 1994; Bell and Grasby, 2012). The causes of this rotation, (see discussion in Bell and Babcock, 1986; Bell and McCallum, 1990; Bell, 1996b; Bell and Grasby, 2012; Bouzidi et al., 2002; Dusseault and Yassir, 1994; Eaton et al., 1999; Halchuk and Mereu, 1990), are not well represented by the model.

Bell and Gough (1979) suggested that the $S_{\text {Hmax }}$ orientation is orthogonal to the topography of the Rocky Mountains, but a comparison close to the topography in the very south of Alberta displays a good fit between the in situ data and the model. They appear more influenced by the overall orientation than by the topography, which is also found by Reiter et al. (2014).

In contrast, the clockwise rotation of about $25^{\circ}$ with respect to the regional trend is obvious close to the Bow Island Arch. Likely this systematic rotation is caused by structural features along the Bow Island Arch which are not incorporated into the model, then by the Rocky Mountain topography.

The Bow Island Arch separates the Alberta Basin and the Walliston Basin. It is a northeastward plunging Precambrian basement feature, which was activated during the Laramiden orogeny and which may be associated with intrusions, similar to Eocene intrusions, about $200 \mathrm{~km}$ to the south in Montana (Podruski, 1988). The systematic $S_{\mathrm{Hmax}}$ rotation in that region is most likely affected by these basement features along the Bow Island Arch.

\subsection{3 $S_{\mathrm{hmin}}$ calibration}

The largest number of stress data are the $S_{\mathrm{hmin}}$ magnitudes $\left(n=1720\right.$, Fig. 12). These, with a few $S_{\text {Hmax }}$ magnitudes ( $n=13-2$ measure and 11 calculated, Fig. 12), are used to find the best-fit magnitudes of the utilized boundary conditions.

A large number of models were tested, but only four of these are shown here (Table 2 and Fig. 15a and b). Based on these four test scenarios with different strain magnitudes, the best-fit model is determined via bivariate regression. 


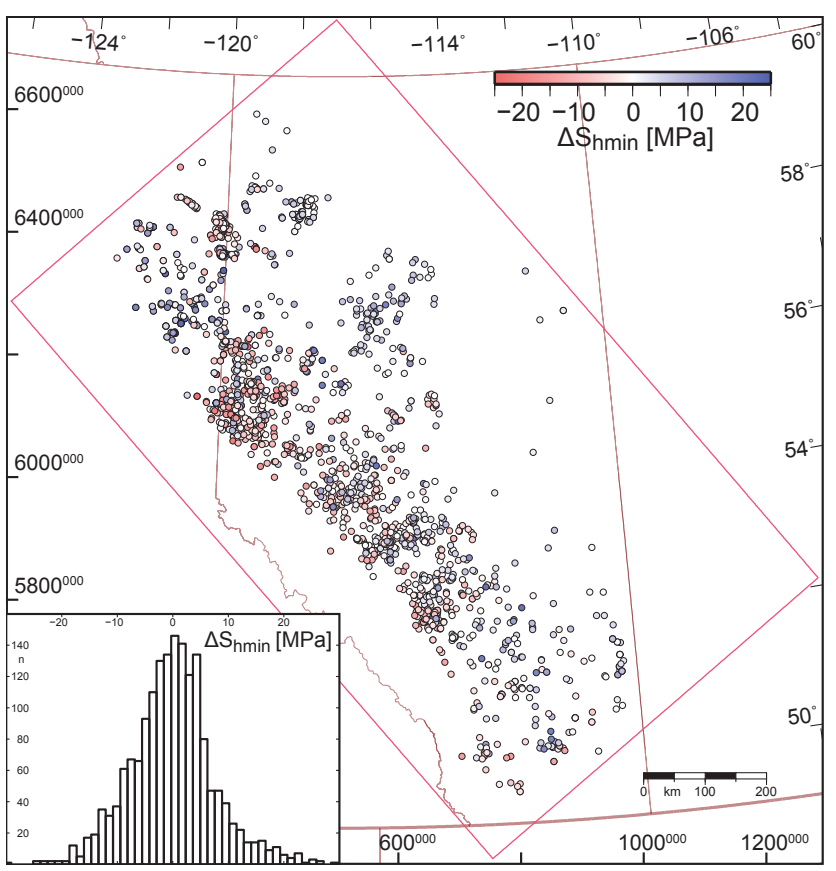

Figure 18. Comparison of the modelled and in situ $S_{\mathrm{hmin}}$ magnitudes, plotted as $\Delta S_{\mathrm{hmin}}$. The map extent is indicated by geographical coordinates (top and right) and by UTM coordinates from zone 11 (left and bottom).

Calculated is the intersection of zero-isolines of $\widetilde{\Delta S}_{\mathrm{Hmax}}$ and $\widetilde{\Delta S}$ Hmin $($ Fig. 15c) based on a plot of push vs. pull (Table 2, Fig. 15a and b). This is possible as linear elastic rheology is used in the model.

An evaluation as to whether the measured $S_{\mathrm{hmin}}$ magnitudes really represent $S_{\mathrm{hmin}}$ or only $\sigma_{3}$, because hydraulic fracturing tests provide the information on the smallest principal stress. The correlation between the in situ $S_{\mathrm{hmin}}$ magnitudes vs. modelled $\sigma_{3}(r=0.837)$ is negligible higher then vs. modelled $S_{\mathrm{hmin}}(r=0.835)$. This indicates that in situ $S_{\mathrm{hmin}}$ measurements in the Alberta Basin likely represent the magnitude of $S_{\mathrm{hmin}}$ and confirms the assumptions for sedimentary basins, being that $S_{\mathrm{hmin}}$ is the smallest principal stress (e.g. Jaeger et al., 2009; McGarr and Gay, 1978; Schmitt et al., 2012).

The spatial distribution of the $\Delta S_{\mathrm{hmin}}$ (Fig. 18) indicates that larger differences between the in situ and modelled magnitudes mainly occur in regions with clustered data. Slightly higher in situ magnitudes are observed in the region $56^{\circ} \mathrm{N}$, $121^{\circ} \mathrm{W}$, in contrast to the slightly lower in situ $S_{\mathrm{hmin}}$ magnitudes in region $55^{\circ} \mathrm{N}, 119^{\circ} \mathrm{W}$.

The $n \Delta S_{\text {hmin }}$ histogram in Fig. $14 \mathrm{c}$ displays a positive screwed distribution. This indicates that the model underestimates a larger portion of the $S_{\mathrm{hmin}}$ magnitudes, in contrast to the in situ data.

To examine deviation reasons, Fig. 19 plots $n \Delta S_{\text {hmin }}$ depending on depth with the measuring method is indicated. In situ $S_{\text {hmin }}$ LOT data provide rather positive $n \Delta S_{\text {hmin }}$ values in shallow depths $(<500 \mathrm{~m})$ and negative values in depth $>500 \mathrm{~m}$ relative to the modelled $S_{\mathrm{hmin}}$ magnitudes. This implies that the model derives smaller magnitudes compared to shallow LOT magnitudes and larger ones with respect to deeper LOT magnitudes. In contrast hydraulic fracturing data did not indicate systematic deviations.

\subsubsection{Deviation of Leak-off test (LOT) data vs. stress model}

There are several reasons for the discrepancy in $S_{\mathrm{hmin}}$ in the in situ LOT data vs. stress model; they are

- the thrust faulting regime $\left(S_{\mathrm{hmin}}>\sigma_{3}\right)$,

- systematic measurement errors,

- systematic model errors, and

- disturbed in situ measurements.

*

\section{Thrust faulting regime $\left(S_{\mathrm{hmin}}>\sigma_{3}\right)$}

Hydraulic fracturing (HF) and leak-off tests (LOT) measure the smallest principal stress $\left(\sigma_{3}\right)$, which is expected as $S_{\mathrm{hmin}}$ in sedimentary basins with normal faulting or strike slip stress regime. In a thrust faulting stress regime, in situ data would underestimate $S_{\mathrm{hmin}}$, as $S_{\mathrm{V}}$ is measured. However, the thrust faulting stress regime is expected in the Rocky Mountains, as well as in and close by the foothills (Bell and Gough, 1979; Bell et al., 1994; Bell and McLellan, 1995; Bell and Bachu, 2003; Bell and Grasby, 2012; Woodland and Bell, 1989) and in shallow depths (up to $600 \mathrm{~m}$ ) (Bell and Babcock, 1986; Fordjor et al., 1983; Jenkins and Kirkpatrick, 1979). Measuring $S_{\mathrm{V}}=\sigma_{3}$ at shallow depths $(<500 \mathrm{~m})$ instead of $S_{\mathrm{hmin}}$ would indicate a thrust faulting regime for some regions, but shallow LOT magnitudes are systematically larger than expected by the stress model, which excludes this attempt at explanation.

*

\section{Systematic measurement errors}

Alternatively, an overestimation of $S_{\text {hmin }}$ by LOT could be explained when the formation breakdown pressure (FBP) or leak-off pressure (LOP) (White et al., 2002) is measured. Additionally, LOT performed at shallow depths $(<300 \mathrm{~m})$ are less reliable, because the tensile strength of the rock plays a more significant role for the measured pressure (Bachu et al., 2008). These reasons would explain larger $S_{\mathrm{hmin}}$ magnitudes from LOT, compared to the model at shallow depths $(<500 \mathrm{~m})$.

LOT are also used as formation integrity tests (FIT) to determine whether the well bore can sustain the stresses expected during drilling and production, and then to determine 


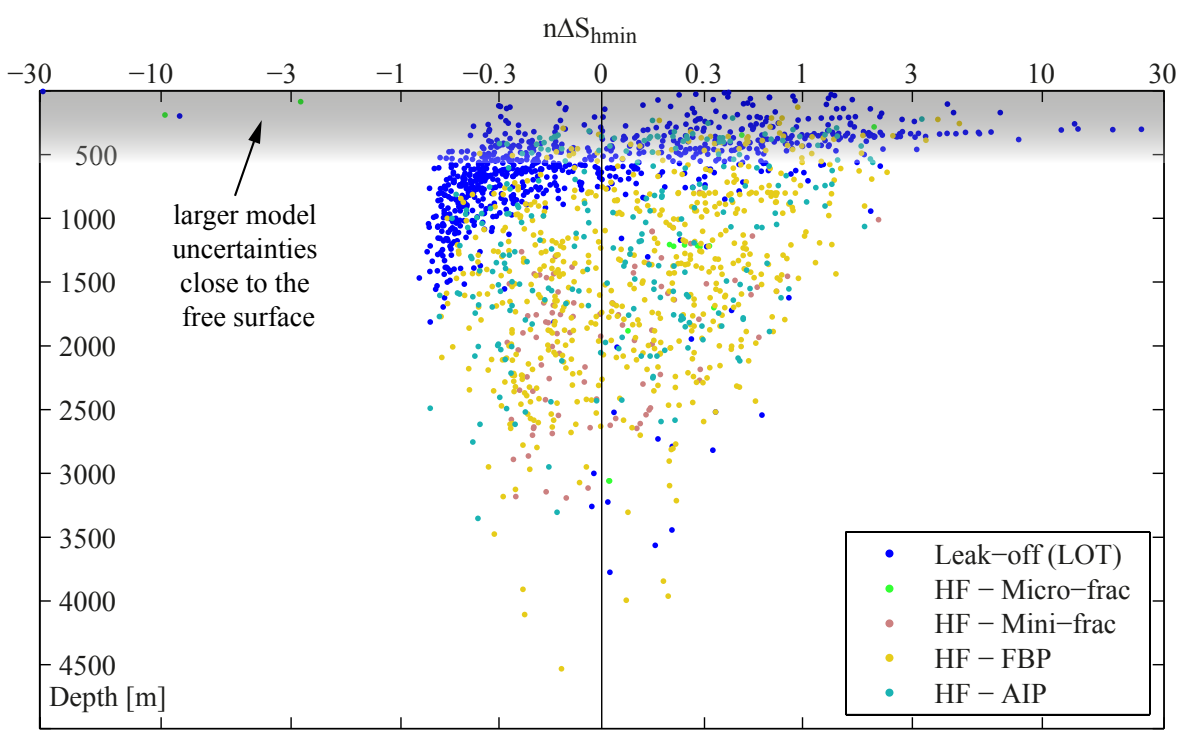

Figure 19. The distribution of the normalized $\Delta S_{\mathrm{hmin}}$ vs. depth, the measurement method is colour coded. Results close to the surface up to about $-500 \mathrm{~m}$ (indicated by greyish haze) have to be interpreted with care, as interpolation of the integration points to the nodes of the finite elements at the surface is problematic. Note that shallow $(<-500 \mathrm{~m})$ leak-off tests (LOT) deliver systematic higher magnitudes than the stress model. In contrast to that are deeper $(>-500 \mathrm{~m})$ LOT data, which have systematically smaller magnitudes as the model. Hydraulic fracturing (HF) data are unconcerned from such systematic drift.

stress magnitudes (e.g. White et al., 2002). Such FIT data derives smaller magnitudes then the formation $S_{\mathrm{hmin}}$ magnitude. Furthermore, poor cement seal between the well bore and the casing close to the LOT can reduce measured magnitude (Edwards et al., 1998). Both reasons could explain smaller $S_{\mathrm{hmin}}$ measurements in greater depth $(>500 \mathrm{~m})$, derived from LOT magnitudes.

*

\section{Systematic model errors}

In situ stresses are affected by the lithology at the locality (Roche et al., 2013; Warpinski, 1989). This is observed in the Alberta Basin, where sandstone exhibits lower in situ $S_{\mathrm{hmin}}$ magnitudes than shale (Bell and Grasby, 2012; Kry and Gronseth, 1983). As the modelled basin has only one material property, likely the evaporate layer, the modelled stresses represent stress conditions from rocks where in situ stress data are derived. These are mainly sandstone and limestone, whereas leak-off tests are usually conducted in shale (Bell and Grasby, 2012). Therefore, the drift could be explained by shallow shale and deeper sandstone or limestone. Furthermore, extrapolation drift close to a free surface of an FEM model are sometimes observed.

*

\section{Disturbed in situ measurements}

Man-made stress changes perturb the juvenile in situ stress due to production (Bell and Grasby, 2012) and injection of fluids (Bachu et al., 2008), besides other mining activity. This is obvious where induced seismicity has been reported (e.g. Baranova et al., 1999; Schultz et al., 2014). Such effects are not restricted to the reservoir alone; the country rock is affected too, in various styles, depending on the relative position (e.g. Segall, 1989).

\subsection{5 $S_{\text {Hmax }}$ calibration}

The quantity and quality of the $S_{\mathrm{Hmax}}$ magnitude data are rather poor compared to the $S_{\mathrm{hmin}}$ magnitude data, but are very helpful for constraining the best-fit model. Otherwise, only a linear best-fit function could be estimated. The two outliers (Fig. 14d) are the only two measured $S_{\mathrm{H} \max }$ magnitude data from Kaiser et al. (1982) at a depth of $152 \mathrm{~m}$ in clay shale. As the measured in situ data are more reasonable then the modelled magnitudes, the reasons for the large deviation are most likely extrapolation problems close to the model surface, as discussed in the previous chapter.

\subsection{Reliability of the predicted 3-D stress field}

The calibration procedure presented in Sect. 5 ensures that the resulting stress field is from a statistically point of view the best-fit model. Nevertheless, there are three main issues that limit the reliability of the model output: (1) The size of the model limits the local resolution. Local structural features such as small faults, material inhomogeneities or stratigraphy are not represented in the model. Thus the predicted stress field in particular close to local structures cannot resolve potential local stress field variations. However, the objective of the large-scale model is to provide boundary and/or 
initial conditions of regional to local stress field model that address the local stress field variations (e.g. Heidbach et al., 2013). (2) The predicted $S_{\mathrm{Hmax}}$ orientations as well as the $S_{\mathrm{V}}$ magnitudes are quite reliable given that density is quite well known (on the level of the resolution of the model) and due to the fact that the wave-length of the $S_{\mathrm{Hmax}}$ orientation is high and only minor affected by local features (Reiter et al., 2014). Also, the reliability of the predicted $S_{\text {hmin }}$ magnitudes is high, due to the large number of available data in the model volume. However, to what extend the $S_{\mathrm{hmin}}$ magnitudes that we use for the calibration of the undisturbed in situ stress are unaffected by production is not clear. Nevertheless, assuming that the majority of these data reflect the in situ stress, the outliers of $S_{\mathrm{hmin}}$ magnitude data that are affected by production are weeded out by the statistic tests. (3) The least reliable stress component of the predicted stress field is the $S_{\mathrm{Hmax}}$ magnitude. Only $13 S_{\mathrm{Hmax}}$ magnitude data were available for the model calibration and these data have much higher inherent uncertainties in comparison with the $S_{\mathrm{hmin}}$ magnitude data. Given this, the statistical fit to the $S_{\mathrm{Hmax}}$ magnitude presented in Figs. 14 and 15 is not well constrained. In particular in areas where $S_{\mathrm{H} \max }$ is close to the $S_{\mathrm{V}}$ magnitude the stress regime is not resolved and might change from strike-slip to normal faulting. This is critical for e.g. borehole stability or for the assessment of potential fault reactivation (Fuchs and Müller, 2001; Moeck and Backers, 2011). This is not a problem of the presented model in particular, but is a key challenge in general as this stress tensor component is hardly constrained from model-independent data.

\subsection{Model variation}

\subsubsection{Impact of fault activation}

The Great Slave Lake Shear Zone (GLS) and the Snowbird Tectonic Zone (STZ) are incorporated within the basement and the basin as vertical contact surfaces. The contact between the Alberta Basin and the foothills (foothill front), as well as the contact of the foothills to the Rocky Mountains (Rock Mountain front), are defined in the model as contact surfaces too. During the model calibration, all these contact surfaces are handled as locked faults with a high friction coefficient. To test the impact of fault re-activation on the stress field, we use in a model variant friction coefficients of 0.3 for STZ and GLS within the basement. For the activation of the basement tectonic zones, the found correlation coefficient for $S_{\mathrm{hmin}}$ has been lowered only slightly: STZ alone $(r=0.808)$, GLS alone $(r=0.828)$ and STZ together with GLS ( $r=0.801)$, compared to the best-fit model $(r=0.835)$. When the friction is lowered at the foothill front $(r=0.836)$ and the Rocky Mountains front $(r=0.835)$ alone, the correlation coefficient did not change. Only when both, the foothill and the Rocky Mountains front are active, the correlation declines $(r=0.701)$.
The $S_{\mathrm{Hmax}}$ orientation changes slightly (up to $2^{\circ}$ ) for all the fault activation. The exception is the Rocky Mountains front, where the $\widetilde{\Delta S}$ Hmax orientation is equal to the best-fit model. This is expected, as only a few $S_{\mathrm{H} \text { max }}$ indicators are derived close to the Rocky Mountains front.

\subsubsection{Impact of Moho depth variation}

To test the influence of the Moho topography (Fig. 5) on the stress state within the Alberta Basin, the best-fit model is modified. The Moho depth is uniform $(z=-50 \mathrm{~km})$ over the entire model region. The results of $\Delta S_{\mathrm{hmin}}$ magnitudes show that this model fits all data, similar to the best-fit model ( $r=0.835$ for both model runs). $S_{\mathrm{Hmax}}$ orientation did not change between the models. Probably, stress magnitudes and orientations are only slightly influenced by the Moho topography in this region.

\subsection{Model application for deep geothermal reservoirs}

To generate electricity, water with temperatures of $120-150^{\circ} \mathrm{C}$ is needed. This requires well depths of 4000-6000 $\mathrm{m}$ in Alberta (Majorowicz and Grasby, 2010a, b). However, stimulation is required to enhance permeabilities (enhanced geothermal systems - EGS) at such depths. Furthermore, less hot water has potential as a domestic heat source.

Three major issues for application of EGS are related to the crustal stresses. These are (1) the orientation of $S_{\mathrm{Hmax}}$, as induced fractures open parallel to $S_{\mathrm{Hmax}}$. This is important for configuration of injection and production wells. (2) The tectonic stress regime determines whether fractures open horizontally (thrust faulting) or vertically (strike slip and normal faulting regime). Furthermore, well stability is a major issue for deep and of course very expensive wells; thus, (3) stress orientation and magnitude as well as differential stresses are important parameters for safe drilling.

$S_{\text {Hmax }}$ orientations have been well understood in the Alberta Basin for decades (e.g. Bell and Gough, 1979; Bell et al., 1994; Fordjor et al., 1983; Reiter et al., 2014), mainly homogeneous in southwest-to-northeast orientation, with the exception of the Peace River Arch, and close to the Bow Island Arch.

Horizontal wells, oriented parallel to $S_{\mathrm{hmin}}$ (southeast to northwest) (Bell and Grasby, 2012) with multiple fractures, open in the $S_{\text {Hmax }}$ direction. This creates several fluid propagation paths, which has the potential to provide cost-efficient energy (Hofmann et al., 2014).

We chose three locations in Alberta that have been identified as possible geothermal sites (Weides and Majorowicz, 2014; Pathak et al., 2013), and show $S_{\mathrm{V}}, S_{\mathrm{hmin}}$ and $S_{\text {Hmax }}$ along the virtual well path (Fig. 20). They are (1) the Edson-Hinton region, with sediment thicknesses of $4000-6000 \mathrm{~m}$ and potential temperatures of $100-150^{\circ} \mathrm{C}$, (2) the village of Leduc, $30 \mathrm{~km}$ south of Edmonton, with the 


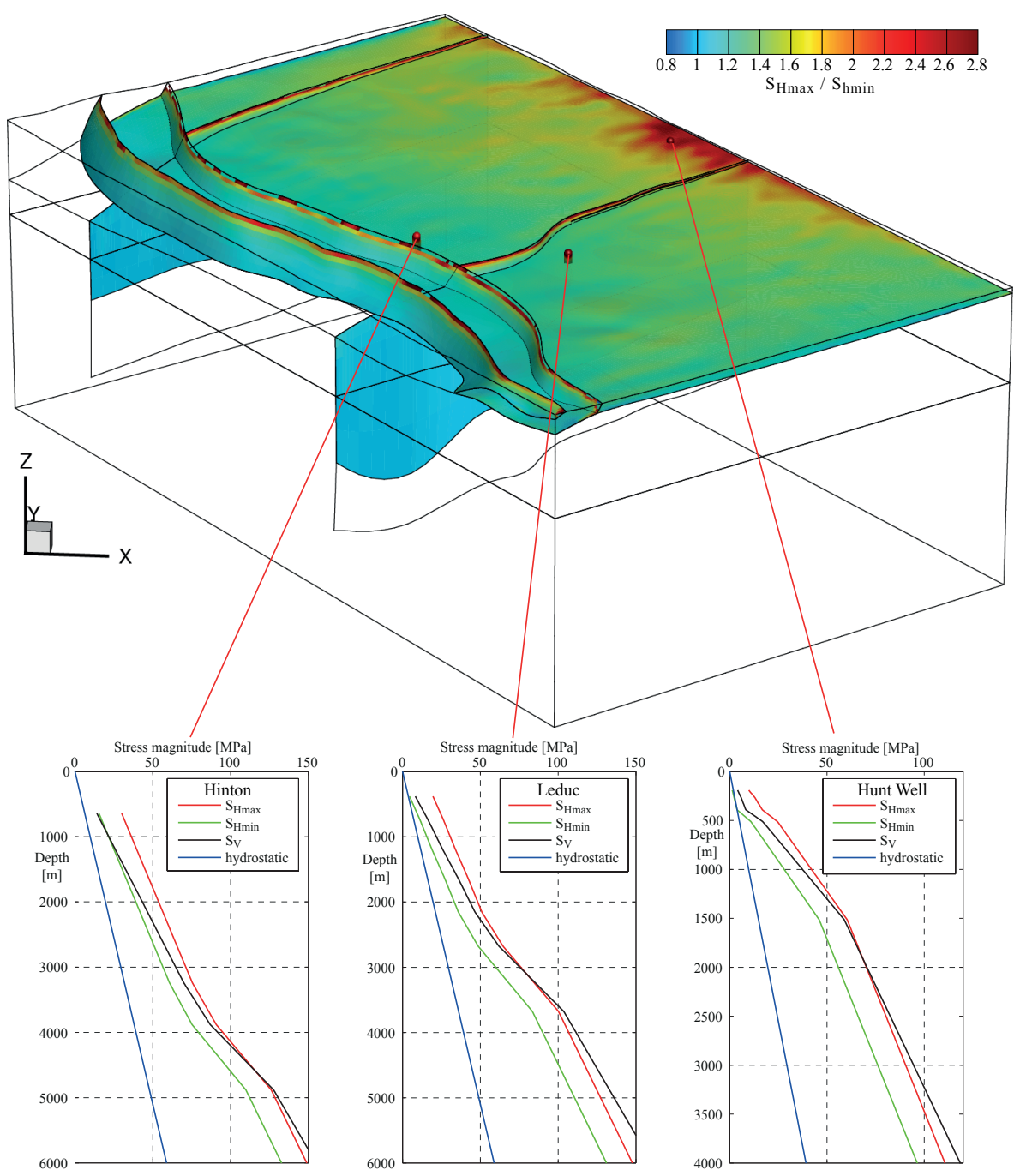

Figure 20. 3-D view of the best-fit model. Displayed is the $S_{\mathrm{Hmax}} / S_{\mathrm{hmin}}$ ratio, plotted at the basement top, along the Snowbird and Great Slave Tectonic Shear Zone, the Rocky Mountains front and the front of the foothills. Three virtual wells from the surface down into the basement are indicated in the model. The stress growth into depth is illustrated in the lower part. These are virtual wells in Hinton, in Leduc ( $30 \mathrm{~km}$ south of Edmonton) and the location of the Hunt well (15 km west of Fort McMurray). The shallowest part is not shown in the plots due to free surface effects.

potential to heat houses (Weides and Majorowicz, 2014), and (3) the Hunt well site (e.g. Majorowicz et al., 2012) close to the town of Fort McMurray, where heat is needed for industrial application (Pathak et al., 2013).

The virtual wells in Fig. 20 show that thrust faulting regimes occur close to the Rocky Mountains and foothills at shallow depths. A strike-slip regime is common within the basin from the surface to about 1500 to $3000 \mathrm{~m}$ in depth and along the foothills from about 1000 to $4000 \mathrm{~m}$ in depth. At greater depths, from about $4500 \mathrm{~m}$ in depth for the foothills, $3000 \mathrm{~m}$ in depth for Edmonton, and $2000 \mathrm{~m}$ in depth for Fort McMurray, a normal faulting regime is expected. This confirms Bell and Gough (1979), Bell et al. (1994), Bell and McLellan (1995), Bell and Babcock (1986), Bell and Bachu (2003), Bell and Grasby (2012), Woodland and Bell
(1989), Fordjor et al. (1983) and Jenkins and Kirkpatrick (1979). Therefore, opening of induced fractures horizontally can be expected only close to the foothills, at depths less than $1000 \mathrm{~m}$.

\section{Conclusions}

A large data set of stress orientation and stress magnitude data is used to calibrate a 3-D geomechanical-numerical model of the Alberta Basin, which provides a good firstorder estimation of the contemporary stress tensor. During calibration procedure, the density of the sediments, the orientation of the displacement boundary conditions, and the magnitude of applied shortening of the model along the 
model boundaries, are calibrated. As linear elastic material properties are used, the magnitude of applied displacement boundary conditions for the best-fit model can be determined by bivariate linear regression. This is based on only three (or more) models with variable boundary conditions. The stochastic verified calibration allows the evaluation of measurement outlier and systematic uncertainties. Variations of the best-fit model suggest that main faults have only local effects on the stresses and that the Moho topography has only a negligible impact on the model results. A systematic drift of $S_{\text {hmin }}$ magnitudes from leak-off tests against the stress model is obvious, but may be affected by multiple reasons.

The best-fit model applies for potential EGS reservoir horizontal wells, oriented northwest to southeast. A virtual well path or cross estimation of the full contemporary stress tensors can be provided by the model in advance of any drilling. The model has the potential to derive boundary conditions for local or reservoir models (e.g. Reiter et al., 2013), where petrological and tectonic inhomogeneities could be respected in more detail. 
Appendix A:

Table A1. Notation.

\begin{tabular}{ll}
\hline$v$ & Poisson's ratio \\
$\boldsymbol{\epsilon}$ & Strain \\
$\rho$ & Density \\
$\sigma$ & Stress at a point \\
$\hat{\sigma}$ & Principal stress \\
$\sigma_{1}, \sigma_{2}, \sigma_{3}$ & Largest, middle and least principal stress \\
$\mathrm{E}$ & Young's modulus \\
$k$ & $k$ ratio $\left(S_{\text {Hmean }} / S_{\mathrm{V}}\right)$ \\
$S_{\mathrm{V}}$ & Vertical stress \\
$S_{\mathrm{Hmax}}$ & Maximum horizontal stress \\
$S_{\mathrm{hmin}}$ & Minimum horizontal stress \\
$S_{\mathrm{Hmean}}$ & Mean horizontal stress \\
$\Delta S$ & Deviation between $S_{\text {measured }}$ and $S_{\text {model }}$ \\
$n \Delta S$ & $\Delta S$ normalized by $S_{\text {model }}$ \\
$\widetilde{\Delta S}$ & Whole model median of $\Delta S$ \\
$\frac{\Delta S}{}$ & Whole model mean of $\Delta S$ \\
\hline
\end{tabular}


Acknowledgements. This study was conducted under the Helmholtz-Alberta Initiative (HAI), to which the first author is grateful for the financial support. We also want to thank the Alberta Geological Survey (AGS), in particular Kristine Haug, who allowed us to use the in situ stress database. We thank Douglas Schmitt, Inga Moek, Dietrich Stromeyer and Tobias Hergert for fruitful discussions about stresses in the Alberta Basin, the modelling approach and technical support. Furthermore, we thank Nathaniel Walsh for spelling and grammar correction. Maps were generated using GMT software (Wessel et al., 2013).

The service charges for this open access publication

have been covered by a Research Centre of the

Helmholtz Association.

Edited by: K. Liu

\section{References}

Adams, J. J.: Canadian Crustal Stress Data: A Compilation to 1987, Tech. rep., Geological Survey of Canada, 1987.

Adams, J. J.: Crustal stresses in eastern Canada, in: Earthquakes at North-Atlantic Passive Margins: Neotectonics and Postglacial Rebound, edited by: Gregersen, S. R. and Basham, P. W., vol. 266, Springer, Netherlands, doi:10.1007/978-94-009-2311-9_17, 289-297, 1989.

Adams, J. J. and Bell, J. S.: Crustal stresses in Canada, in: Neotectonics of North America, Decade of North American Neotectonics of North America, edited by: Slemmons, D. B. and Engdahl, E. R., Geological Society of America, doi:10.1007/978-94009-2311-9_17, chap. 20, 367-386, 1991.

Altmann, J. B., Müller, T. M., Müller, B. I., Tingay, M. R. P., and Heidbach, O.: Poroelastic contribution to the reservoir stress path, Int. J. Rock Mech. Min., 47, 1104-1113, doi:10.1016/j.ijrmms.2010.08.001, 2010.

Amadei, B. and Stephansson, O.: Rock Stress and Its Measurement, Chapman \& Hall, London, 1997.

Anderson, E. M.: The Dynamics of Faulting and Dyke Formation with Application to Britain, 2nd edn., Oliver and Boyd, London, Edinburgh, 1951.

Aulbach, S., Griffin, W., O'Reilly, S., and McCandless, T. E.: Genesis and evolution of the lithospheric mantle beneath the Buffalo Head Terrane, Alberta (Canada), Lithos, 77, 413-451, doi:10.1016/j.lithos.2004.04.020, 2004.

Bachu, S., Haug, K., and Michael, K.: Stress Regime at Acid-Gas Injection Operations in Western Canada, ERCB/AGS Special Report 094, Energy Resources Conservation Board, pp. 49, 2008.

Baranova, V., Mustaqeem, A., and Bell, J. S.: A model for induced seismicity caused by hydrocarbon production in the Western Canada Sedimentary Basin, Can. J. Earth Sci., 36, 47-64, doi:10.1139/cjes-36-1-47, 1999.

Barton, C. A. and Moos, D.: Geomechanical wellbore imaging: key to managing the asset life cycle, Tech. rep., GeoMechanics International, 2010.

Bell, J. S.: Offset boreholes in the Rocky mountains of Alberta, Canada, Geology, 13, 734-737, doi:10.1130/00917613(1985)13<734:OBITRM>2.0.CO;2, 1985.

Bell, J. S.: Attached and detached in-situ stress regimes in sedimentary basins, in: 55th EAEG Meeting, 1993.
Bell, J. S.: In situ stresses in sedimentary rocks (part 1); measurement techniques, Geosc. Can., 23, 85-100, 1996a.

Bell, J. S.: In situ stresses in sedimentary rocks (part 2): applications of stress measurements, Geosci. Can., 23, 135-153, 1996b.

Bell, J. S. and Babcock, E. A.: The stress regime of the Western Canadian Basin and implications for hydrocarbon production, B. Can. Petrol. Geol., 34, 364-378, 1986.

Bell, J. S. and Bachu, S.: In situ stress magnitude and orientation estimates for Cretaceous coal-bearing strata beneath the plains area of central and southern Alberta, B. Can. Petrol. Geol., 51, 1-28, doi:10.2113/gscpgbull.51.1.1, 2003.

Bell, J. S. and Bachu, S.: In-situ stress magnitudes in the Alberta Basin-regional coverage for petroleum engineers, in: Proceedings of Canadian International Petroleum Conference, Society of Petroleum Engineers, Calgary, doi:10.2118/2004-155, 1-12, 2004.

Bell, J. S. and Gough, D. I.: Northeast-southwest compressive stress in Alberta evidence from oil wells, Earth Planet. Sc. Lett., 45, 475-482, doi:10.1016/0012-821X(79)90146-8, 1979.

Bell, J. S. and Gough, D.: Intraplate stress orientations from Alberta oil-wells, Geodynamics, 5, 96-104, doi:10.1029/GD005p0096, 1981.

Bell, J. S. and Grasby, S. E.: The stress regime of the Western Canadian Sedimentary Basin, Geofluids, 12, 150-165, doi:10.1111/j.1468-8123.2011.00349.x, 2012.

Bell, J. S. and McCallum, R.: In situ stress in the Peace River Arch area, Western Canada, B. Can. Petrol. Geol., 38, 270-281, 1990.

Bell, J. S. and McLellan, P. J.: Exploration and production implications of subsurface rock stresses in western Canada, in: Proceedings of the Oil and Gas Forum, p. 5, 1995.

Bell, J. S., Price, R. A., and McLellan, P. J.: In-situ stress in the Western Canada Sedimentary Basin, in: Geological Atlas of the Western Canada Sedimentary Basin, edited by: Mossop, G. D. and Shetsen, I., Canadian Society of Petroleum Geologists and Alberta Research Council, Alberta, chap. 29, 439-446, 1994.

Boerner, D., Kurtz, R., Craven, J., Ross, G., and Jones, F.: A synthesis of electromagnetic studies in the Lithoprobe Alberta Basement Transect: constraints on Paleoproterozoic indentation tectonics, Can. J. Earth Sci., 37, 1509-1534, doi:10.1139/cjes-3711-1509, 2000.

Bouzidi, Y., Schmitt, D. R., Burwash, R. A., and Kanasewich, E. R.: Depth migration of deep seismic reflection profiles: crustal thickness variations in Alberta, Can. J. Earth Sci., 39, 331-350, doi:10.1139/e01-080, 2002.

Brown, D. W.: Hot dry rock geothermal energy: important lessons from Fenton Hill, in: Thirty-Fourth Workshop on Geothermal Reservoir Engineering, Stanford, 3-6, 2009.

Brown, E. and Hoek, E.: Trends in relationships between measured in-situ stresses and depth, Int. J. Rock Mech. Min., 15, 211-215, 1978.

Brudy, M. and Kjørholt, H.: Stress orientation on the Norwegian continental shelf derived from borehole failures observed in high-resolution borehole imaging logs, Tectonophysics, 337, 65-84, doi:10.1016/S0040-1951(00)00299-7, 2001.

Brudy, M., Zoback, M. D., Fuchs, K., Rummel, F., and Baumgärtner, J.: Estimation of the complete stress tensor to $8 \mathrm{~km}$ depth in the KTB scientific drill holes: Implications for crustal strength, J. Geophys. Res., 102, 18453-18475, 1997. 
Buchmann, T. J. and Connolly, P. T.: Contemporary kinematics of the Upper Rhine Graben: A 3-D finite element approach, Global Planet. Change, 58, 287-309, doi:10.1016/j.gloplacha.2007.02.012, 2007.

Burianyk, M. J., Kanasewich, E. R., and Udey, N.: Broadside wideangle seismic studies and three-dimensional structure of the crust in the southeast Canadian Cordillera, Can. J. Earth Sci., 34, 1156-1166, doi:10.1139/e17-093, 1997.

Camelbeeck, T., de Viron, O., Van Camp, M., and Kusters, D.: Local stress sources in Western Europe lithosphere from geoid anomalies, Lithosphere, 5, 235-246, doi:10.1130/L238.1, 2013.

Chacko, T., De, S. K., Creaser, R. A., and Muehlenbachs, K.: Tectonic setting of the Taltson magmatic zone at 1.9-2.0 Ga: a granitoid-based perspective, Can. J. Earth Sci., 37, 1597-1609, doi:10.1139/cjes-37-11-1597, 2000.

Clowes, R. M., Burianyk, M. J., Gorman, A. R., and Kanasewich, E. R.: Crustal velocity structure from SAREX, the southern Alberta refraction experiment, Can. J. Earth Sci., 39, 351-373, doi:10.1139/E01-070, 2002.

Coblentz, D. D. and Richardson, R. M.: Analysis of the South American intraplate stress field, J. Geophys. Res., 101, 8643-8657, doi:10.1029/96JB00090, 1996.

Corrigan, D., Hajnal, Z., Németh, B., and Lucas, S.: Tectonic framework of a Paleoproterozoic arc-continent to continentcontinent collisional zone, Trans-Hudson Orogen, from geological and seismic reflection studies, Can. J. Earth Sci., 42, 421-434, doi:10.1139/E05-025, 2005.

Dalton, C. A., Gaherty, J. B., and Courtier, A. M.: Crustal Vs structure in northwestern Canada: imaging the Cordillera-craton transition with ambient noise tomography, J. Geophys. Res., 116, B12315, doi:10.1029/2011JB008499, 2011.

Duchane, D. and Brown, D.: Hot dry rock (HDR) geothermal energy research and development at Fenton Hill, New Mexico, Geo-Heat Centre Quarterly Bulletin, 23, 13-19, 2002.

Dusseault, M. B. and Yassir, N. A.: Effects of rock anisotropy and heterogeneity on stress distributions at selected sites in North America, Eng. Geol., 37, 181-197, doi:10.1016/00137952(94)90055-8, 1994

Dyksterhuis, S., Albert, R., and Müller, R. D.: Finiteelement modelling of contemporary and palaeo-intraplate stress using ABAQUS ${ }^{\mathrm{TM}}$, Comput. Geosci., 31, 297-307, doi:10.1016/j.cageo.2004.10.011, 2005

Eaton, D. W., Ross, G. M., and Hope, J.: The rise and fall of a cratonic arch: A regional seismic perspective on the Peace River Arch, Alberta, B. Can. Petrol. Geol., 47, 346-361, 1999.

Edwards, S., Meredith, P., and Murrell, S.: An investigation of leak-off test data for estimating in-situ stress magnitudes: application to a basinwide study in the North Sea, in: Proceedings of SPE/ISRM Rock Mechchanics in Petroleum Engineering, Society of Petroleum Engineers, Trondheim, 8-10 July, doi:10.2118/47272-MS, 357-365, 1998.

England, T. and Bustin, R.: Effect of thrust faulting on organic maturation in the southeastern Canadian Cordillera, Org. Geochem., 10, 609-616, 1986.

English, J. M. and Johnston, S. T.: The Laramide Orogeny: what were the driving forces?, Int. Geol. Rev., 46, 833-838, doi:10.2747/0020-6814.46.9.833, 2004

Fernández-Viejo, G., and Clowes, R. M.: Lithospheric structure beneath the Archaean Slave Province and Proterozoic
Wopmay orogen, northwestern Canada, from a lithoprobe refraction/wide-angle reflection survey, Geophys. J. Int., 153, 1-19, doi:10.1046/j.1365-246X.2003.01807.x, 2003.

Fischer, K. and Henk, A.: A workflow for building and calibrating 3-D geomechanical models - a case study for a gas reservoir in the North German Basin, Solid Earth, 4, 347-355, doi:10.5194/se-4-347-2013, 2013.

Flesch, L. M., Holt, W. E., Haines, A. J., Wen, L., and Shen-Tu, B.: The dynamics of western North America: stress magnitudes and the relative role of gravitational potential energy, plate interaction at the boundary and basal tractions, Geophys. J. Int., 169, 866-896, doi:10.1111/j.1365-246X.2007.03274.x, 2007.

Flowers, R. M., Ault, A. K., Kelley, S. A., Zhang, N., and Zhong, S.: Epeirogeny or eustasy? Paleozoic-Mesozoic vertical motion of the North American continental interior from thermochronometry and implications for mantle dynamics, Earth Planet. Sc. Lett., 317-318, 436-445, doi:10.1016/j.epsl.2011.11.015, 2012.

Fordjor, C. K., Bell, J. S., and Gough, D. I.: Breakouts in Alberta and stress in the North American plate, Can. J. Earth Sci., 20, 1445-1455, doi:10.1139/e83-130, 1983.

Fossen, H.: Structural Geology, Cambridge University Press, 2010.

Fuchs, K. and Müller, B.: World stress map of the Earth: a key to tectonic processes and technological applications, Naturwissenschaften, 88, 357-371, doi:10.1007/s001140100253, 2001.

Gabrielse, H. and Yorath, C.: The Cordilleran Orogen in Canada, Geosci. Can., 16, 67-83, 1989.

Gardner, J. and Dumanoir, J.: Litho-density log interpretation, in: SPWLA 21st Annual Logging Symposium, Society of Petrophysicists and Well-Log Analysts, Lafayette, Louisiana, 1-23, 1980.

Gay, N. C.: In-situ stress measurements in Southern Africa, Tectonophysics, 29, 447-459, doi:10.1016/00401951(75)90173-0, 1975.

Ghosh, A., Holt, W. E., and Flesch, L. M.: Contribution of gravitational potential energy differences to the global stress field, Geophys. J. Int., 179, 787-812, doi:10.1111/j.1365246X.2009.04326.x, 2009.

Gough, D. I.: Mantle upflow under North America and plate dynamics, Nature, 311, 428-433, doi:10.1038/311428a0, 1984.

Gough, D. I., Fordjor, C. K., and Bell, J. S.: A stress province boundary and tractions on the North American plate, Nature, 305, 619-621, doi:10.1038/305619a0, 1983.

Grobe, M.: Distribution and thickness of salt within the Devonian Elk Point Group, Tech. rep., Alberta Energy and Utilities Board, Alberta Geological Survey, Edmonton, p. 35, 2000.

Gronseth, J. and Kry, P.: Instaneous shut-in pressure and its relationship to the minimum in-situ stress, in: Hydraulic Fracturing Stress Measurements, edited by: Zoback, M. D. and Haimson, B., US Nat. Comm. Rock Mechanics, Nat. Acad. Press, 55-60, 1983.

Gu, Y. J., Okeler, A., Shen, L., and Contenti, S.: The Canadian Rockies and Alberta Network (CRANE): new constraints on the Rockies and Western Canada Sedimentary Basin, Seismol. Res. Lett., 82, 575-588, doi:10.1785/gssrl.82.4.575, 2011.

Gunzburger, Y. and Magnenet, V.: Stress inversion and basement-cover stress transmission across weak layers in the Paris basin, France, Tectonophysics, 617, 44-57, doi:10.1016/j.tecto.2014.01.016, 2014. 
Haimson, B. C. and Cornet, F.: ISRM Suggested Methods for rock stress estimation - Part 3: hydraulic fracturing (HF) and/or hydraulic testing of pre-existing fractures (HTPF), Int. J. Rock Mech. Min., 40, 1011-1020, doi:10.1016/j.ijrmms.2003.08.002, 2003.

Haimson, B. C. and Fairhurst, C.: In-situ stress determination at great depth by means of hydraulic fracturing, in: The 11th US Symposium on Rock Mechechanics (USRMS), Berkeley, California, 16-19 June, American Rock Mechchanics Association, 559-584, 1969.

Hajnal, Z., Lewry, J., White, D. J., Ashton, K. E., Clowes, R. M., Stauffer, M., Gyorfi, I., and Takacs, E.: The Sask Craton and Hearne Province margin: seismic reflection studies in the western Trans-Hudson Orogen, Can. J. Earth Sci., 42, 403-419, doi:10.1139/E05-026, 2005.

Halchuk, S. and Mereu, R.: A seismic investigation of the crust and Moho underlying the Peace River Arch, Canada, Tectonophysics, 185, 1-19, doi:10.1016/0040-1951(90)90401-S, 1990.

Hamilton, W., Langenberg, C., Price, M., and Chao, D.: Geological Map of Alberta, Tech. rep., Alberta Geological Survey, Edmonton, 1999.

Hawkes, C. D., Bachu, S., Haug, K., and Thompson, A. W.: Analysis of in-situ stress regime in the Alberta Basin, Canada, for performance assessment of $\mathrm{CO}_{2}$ geological sequestration sites, in: Proceedings of the Fourth Annual Conference on Carbon Capture and Sequestration DOE/NETL, p. 22, 2005.

Heidbach, O., Reinecker, J., Tingay, M. R. P., Müller, B., Sperner, B., Fuchs, K., and Wenzel, F.: Plate boundary forces are not enough: second- and third-order stress patterns highlighted in the World Stress Map database, Tectonics, 26, 1-19, doi:10.1029/2007TC002133, 2007.

Heidbach, O., Tingay, M. R. P., Barth, A., Reinecker, J., Kurfeß, D., and Müller, B.: Global crustal stress pattern based on the World Stress Map database release 2008, Tectonophysics, 482, 3-15, doi:10.1016/j.tecto.2009.07.023, 2010.

Heidbach, O., Hergert, T., Reinecker, J., Reiter, K., Giger, S., Vietor, T., and Marschall, P.: In situ stress in Switzerland from pointwise field data to a 3-D continuous quantification, in: International Workshop on Geomechanics and Energy The Ground as Energy Source and Storage, EAGE, Lausanne, doi:10.3997/2214-4609.20131977, 1-4, 2013.

Heim, A.: Untersuchungen über den Mechanismus der Gebirgsbildung: im Anschluss an die geologische Monographie der Tödi-Windgällen-Gruppe, Benno Schwabe Verlagsbuchhandlung, Basel, 1878.

Henk, A.: Pre-drilling prediction of the tectonic stress field with geomechanical models, first break, 23, 53-57, doi:10.3997/13652397.2005021, 2005.

Henton, J. A., Craymer, M. R., Ferland, R., Dragert, H., Mazzotti, S., and Forbes, D. L.: Crustal motion and deformation monitoring of the Canadian landmass, Geomatica, 60, 173-191, 2006.

Hergert, T. and Heidbach, O.: Geomechanical model of the Marmara Sea region-II. 3-D contemporary background stress field, Geophys. J. Int., 185, 1090-1102, doi:10.1111/j.1365246X.2011.04992.x, 2011.

Hickman, S. and Zoback, M. D.: Stress orientations and magnitudes in the SAFOD pilot hole, Geophys. Res. Lett., 31, L15S12, doi:10.1029/2004GL020043, 2004.
Hoffman, P. F.: Precambrian geology and tectonic history of North America, in: The Geology of North America, The Geological Society of America, 447-512, 1989.

Hofmann, H., Weides, S., Babadagli, T., Zimmermann, G., Moeck, I., Majorowicz, J., and Unsworth, M.: Potential for enhanced geothermal systems in Alberta, Canada, Energy, 69, 578-591, doi:10.1016/j.energy.2014.03.053, 2014.

Hubbert, M. K. and Willis, D. G.: Mechanics of hydraulic fracturing, AIME Trans, 210, 153-168, 1957.

Humphreys, E. D. and Coblentz, D. D.: North American dynamics and western U. S. tectonics, Rev. Geophys., 45, p. 30, doi:10.1029/2005RG000181, 2007.

Hyndman, R. D., Currie, C. A., Mazzotti, S., and Frederiksen, A.: Temperature control of continental lithosphere elastic thickness, Te vs Vs, Earth Planet. Sc. Lett., 277, 539-548, doi:10.1016/j.eps1.2008.11.023, 2009.

Jaeger, J., Cook, N., and Zimmerman, R.: Fundamentals of Rock Mechechanics, John Wiley \& Sons, 2009.

Jarosinski, M., Beekman, F., Bada, G., and Cloetingh, S.: Redistribution of recent collision push and ridge push in Central Europe: insights from FEM modelling, Geophys. J. Int., 167, 860-880, doi:10.1111/j.1365-246X.2006.02979.x, 2006.

Jenkins, G. and Kirkpatrick, J.: Mbustion Project, J. Can. Petrol. Technol., 18, 85-94, doi:10.2118/79-02-07, 1979.

Kaiser, P., Mackay, C., and Morgenstern, N.: Performance of a shaft in weak rock (Bearpa W Shale), in: ISRM International Symposium, Aachen, Germany, 26-28 May, 613-622, 1982.

Kanamori, H. and Brodsky, E. E.: The physics of earthquakes, Rep. Prog. Phys., 67, 1429-1496, doi:10.1088/0034-4885/67/8/R03, 2004.

King, M.: Static and dynamic elastic properties of rocks from the Canadian Shield, Int. J. Rock Mech. Min., 20, 237-241, 1983.

Kry, P. and Gronseth, J.: In-situ stresses and hydraulic fracturing in the Deep Basin, J. Can. Petrol. Technol., 22, 31-35, doi:10.2118/83-06-02, 1983.

Leckie, D. A. and Smith, D. G.: Regional setting, evolution, and depositional cycles of the Western Canada Foreland Basin, in: Foreland Basins and Fold Belts, edited by: Macqueen, R. W. and Leckie, D. A., vol. A136, American Association of Petroleum Geologists, chap. 1, 9-46, 1992.

Legarth, B., Huenges, E., and Zimmermann, G.: Hydraulic fracturing in a sedimentary geothermal reservoir: results and implications, Int. J. Rock Mech. Min., 42, 1028-1041, doi:10.1016/j.ijrmms.2005.05.014, 2005.

Li, G., Lorwongngam, A., and Roegiers, J.: Critical review of leakoff test as a practice for determination of in-situ stresses, in: 43rd US Rock Mechchanics Symposium and 4th US-Canada Rock Mechanics Symposium, American Rock Mechanics Association, Asheville, p. 5, 2009.

Lindner, E. N. and Halpern, J. A.: In-situ stress in north America: A compilation, Int. J. Rock Mech. Min., 15, 183-203, 1978.

Ljunggren, C., Chang, Y., Janson, T., and Christiansson, R.: An overview of rock stress measurement methods, Int. J. Rock Mech. Min., 40, 975-989, doi:10.1016/j.ijrmms.2003.07.003, 2003.

Majorowicz, J. and Grasby, S. E.: Heat flow, depth-temperature variations and stored thermal energy for enhanced geothermal systems in Canada, J. Geophys. Eng., 7, 232-241, doi:10.1088/1742-2132/7/3/002, 2010a. 
Majorowicz, J. and Grasby, S. E.: High potential regions for enhanced geothermal systems in Canada, Nat. Resour. Res., 19, 177-188, doi:10.1007/s11053-010-9119-8, 2010b.

Majorowicz, J., Gosnold, W., Gray, A. D., Safanda, J., Klenner, R., and Unsworth, M. J.: Implications of post-glacial warming for northern Alberta heat flow-correcting for the underestimate of the geothermal potential, Geoth. Res. T., 36, 693-698, 2012.

Mallet, J.-L.: Discrete smooth interpolation in geometric modelling, Comput. Aided Design, 24, 178-191, doi:10.1016/00104485(92)90054-E, 1992.

Mallet, J.-L.: Geomodeling, Oxford University Press, New York, 2002.

Mavko, G., Mukerji, T., and Dvorkin, J.: The Rock Physics Handbook: Tools for Seismic Analysis of Porous Media, Cambridge University Press, Cambridge, 2009.

Mazzotti, S., Leonard, L. J., Cassidy, J. F., Rogers, G. C., and Halchuk, S.: Seismic hazard in western Canada from GPS strain rates versus earthquake catalog, J. Geophys. Res., 116, B12310, doi:10.1029/2011JB008213, 2011.

McGarr, A. and Gay, N. C.: State of stress in the earth's crust, Annu. Rev. Earth Pl. Sc., 6, 405-436, 1978.

McLellan, P.: In-situ stress prediction and measurement by hydraulic fracturing, Wapiti, Alberta, in: Proceedings of Annual Technical Meeting, Society of Petroleum Engineers, Calgary, doi:10.2118/87-38-58, 967-933, 1987.

Meijer Drees, N. C.: Devonian Elk Point Group of the Western Canada Sedimentary Basin, in: Geological Atlas of the Western Canada Sedimentary Basin, edited by: Mossop, G. D. and Shetsen, I., Canadian Society of Petroleum Geologists and Alberta Research Council, Alberta, chap. 10, 129-147, 1994.

Moeck, I. and Backers, T.: Fault reactivation potential as a critical factor during reservoir stimulation, First Break, 1789, 73-80, doi:10.3997/1365-2397.2011014, 2011.

Mossop, G. D. and Shetsen, I. (Eds.): Geological Atlas of the Western Canada Sedimentary Basin, Canadian Society of Petroleum Geologists and Alberta Research Council, 1994a.

Mossop, G. D. and Shetsen, I.: Introduction to the geological atlas of the Western Canada Sedimentary Basin, in: Geological Atlas of the Western Canada Sedimentary Basin, edited by: Mossop, G. D. and Shetsen, I., Canadian Society of Petroleum Geologists and Alberta Research Council, Alberta, chap. 1, 1-11, 1994b.

Müller, B., Wehrle, V., Zeyen, H., and Fuchs, K.: Short-scale variations of tectonic regimes in the western European stress province north of the Alps and Pyrenees, Tectonophysics, 275, 199-219, doi:10.1016/S0040-1951(97)00021-8, 1997.

Naliboff, J., Lithgow-Bertelloni, C., Ruff, L., and de Koker, N.: The effects of lithospheric thickness and density structure on Earth's stress field, Geophys. J. Int., 188, 1-17, doi:10.1111/j.1365246X.2011.05248.x, 2012.

Németh, B., Hajnal, Z., and Lucas, S.: Moho signature from wideangle reflections: preliminary results of the 1993 Trans-Hudson Orogen refraction experiment, Tectonophysics, 264, 111-121, doi:10.1016/S0040-1951(96)00121-7, 1996.

Németh, B., Clowes, R. M., and Hajnal, Z.: Lithospheric structure of the Trans-Hudson Orogen from seismic refraction wide-angle reflection studies, Can. J. Earth Sci., 42, 435-456, doi:10.1139/e05-032, 2005.
Nurkowski, J. R.: Coal quality, coal rank variation and its relation to reconstructed overburden, upper Cretaceous and Tertiary plains coals, Alberta, Canada, AAPG Bull., 68, 285-295, 1984.

Obert, L.: In situ determination of stress in rock, Min. Eng.Littleton, 14, 51-58, 1962.

Okrusch, M. and Matthes, S.: Mineralogie, Springer-Lehrbuch, Springer-Verlag, Berlin, Heidelberg, doi:10.1007/b139038, 2005.

Orlic, B. and Wassing, B. B. T.: A study of stress change and fault slip in producing gas reservoirs overlain by elastic and viscoelastic caprocks, Rock Mech. Rock Eng., 46, 421-435, doi:10.1007/s00603-012-0347-6, 2012.

Parsons, T.: Tectonic stressing in California modeled from GPS observations, J. Geophys. Res., 111, 1-16, doi:10.1029/2005JB003946, 2006.

Pathak, V., Babadagli, T., Majorowicz, J. A., and Unsworth, M. J.: Evaluation of engineered geothermal systems as a heat source for oil sands production in Northern Alberta, Nat. Resour. Res., 23, 247-265, doi:10.1007/s11053-013-9218-4, 2013.

Peska, P. and Zoback, M. D.: Compressive and tensile failure of inclined well bores and determination of in situ stress and rock strength, J. Geophys. Res., 100, 12791-12811, doi:10.1029/95JB00319, 1995.

Podruski, J.: Contrasting character of the Peace River and Sweetgrass Arches, Western Canada Sedimentary Basin, Geosci. Can., 15, 94-97, 1988.

Porter, J. W., Price, R. A., and McCrossan, R. G.: The Western Canada Sedimentary Basin, Philos. T. R. Soc. Lond., 305, 169-192, 1982.

Poulton, T., Christopher, J., Hays, B., Losert, J., Tittemore, J., and Gilchrist, R.: Jurassic and lowermost Cretaceous Strata of the Western Canada Sedimentary Basin, in: Geological Atlas of the Western Canada Sedimentary Basin, edited by: Mossop, G. D. and Shetsen, I., Canadian Society of Petroleum Geologists and Alberta Research Council, Alberta, chap. 18, 297-316, 1994.

Price, R. A.: The Cordilleran foreland thrust and fold belt in the southern Canadian Rocky Mountains, Geol. Soc. Spec. Publ., 9, 427-448, doi:10.1144/GSL.SP.1981.009.01.39, 1981.

Price, R. A.: Cordilleran tectonics and the evolution of the Western Canada Sedimentary Basin, in: Geological Atlas of the Western Canada Sedimentary Basin, edited by: Mossop, G. D. and Shetsen, I., Canadian Society of Petroleum Geologists and Alberta Research Council, chap. 2, 13-24, 1994.

Reiter, K., Heidbach, O., and Moeck, I.: Stress field modelling in the Alberta Basin, Canada, in: International Workshop on Geomechanics and Energy - The Ground as Energy Source and Storage, EAGE, Lausanne, doi:10.3997/2214-4609.20131973, 26-28, 2013.

Reiter, K., Heidbach, O., Schmitt, D. R., Haug, K., Ziegler, M., and Moeck, I.: A revised crustal stress orientation database for Canada, Tectonophysics, 636, 111-124, doi:10.1016/j.tecto.2014.08.006, 2014.

Richardson, R. M.: Ridge forces, absolute plate motions, and the intraplate stress field, J. Geophys. Res., 97, 11739-11748, doi:10.1029/91JB00475, 1992.

Ristau, J., Rogers, G. C., and Cassidy, J. F.: Stress in western Canada from regional moment tensor analysis, Can. J. Earth Sci., 44, 127-148, doi:10.1139/e06-057, 2007. 
Roche, V., Homberg, C., and Rocher, M.: Fault nucleation, restriction, and aspect ratio in layered sections: quantification of the strength and stiffness roles using numerical modeling, J. Geophys. Res.-Sol. Ea., 118, 4446-4460, doi:10.1002/jgrb.50279, 2013.

Röckel, T. and Lempp, C.: Der Spannungszustand im Norddeutschen Becken, Erdöl Erdgas Kohle, 119, 73-80, 2003.

Ross, G. M., Broome, J., and Miles, W.: Potential fields and basement structure - Western Canada Sedimentary Basin, in: Geological Atlas of the Western Canada Sedimentary Basin, edited by: Mossop, G. D. and Shetsen, I., Canadian Society of Petroleum Geologists and Alberta Research Council, Alberta, chap. 4, 41-47, 1994.

Ross, G. M., Eaton, D. W., Boerner, D. E., and Miles, W.: Tectonic entrapment and its role in the evolution of continental lithosphere: an example from the Precambrian of western Canada, Tectonics, 19, 116-134, doi:10.1029/1999TC900047, 2000.

Ross, M., Parent, M. and Lefebvre, R.: 3D geologic framework models for regional hydrogeology and land-use management: a case study from a Quaternary basin of southwestern Quebec, Canada, Hydrogeology Journal, 13, 690-707, doi:10.1007/s10040-004-0365-x, 2004.

Roth, F. and Fleckenstein, P.: Stress orientations found in north-east Germany differ from the West European trend, Terra Nova, 13, 289-296, doi:10.1046/j.1365-3121.2001.00357.x, 2001.

Sami, T. T. and James, N. P.: Evolution of an early Proterozoic foreland basin carbonate platform, lower Pethei Group, Great Slave Lake, north-west Canada, Sedimentology, 40, 403-430, doi:10.1111/j.1365-3091.1993.tb01343.x, 1993.

Sbar, M. L. and Sykes, L. R.: Contemporary compressive stress and seismicity in eastern North America: an example of intra-plate tectonics, Geol. Soc. Am. Bull., 84, 1861-1882, doi:10.1130/0016-7606(1973)84<1861:CCSASI>2.0.CO;2, 1973.

Schmitt, D. R., Currie, C. A., and Zhang, L.: Crustal stress determination from boreholes and rock cores: fundamental principles, Tectonophysics, 580, 1-26, doi:10.1016/j.tecto.2012.08.029, 2012.

Schultz, R., Stern, V., and Gu, Y. J.: An investigation of seismicity clustered near the Cordel Field, west-central Alberta and its relation to a nearby disposal well, J. Geophys. Res.-Sol. Ea., 119, 1-14, doi:10.1002/2013JB010836, 2014.

Segall, P.: Earthquakes triggered by fluid extraction, Geology, 17, 942-946, 1989.

Sheorey, P.: A theory for in situ stresses in isotropic and transverseley isotropic rock, Int. J. Rock Mech. Min., 31, 23-34, doi:10.1016/0148-9062(94)92312-4, 1994.

Shragge, J., Bostock, M. G., Bank, C.-G., and Ellis, R. M.: Integrated teleseismic studies of the southern Alberta upper mantle, Can. J. Earth Sci., 39, 399-411, doi:10.1139/e01-084, 2002.

Smith, D.: Paleogeographic evolution of the Western Canada Foreland Basin, in: Geological Atlas of the Western Canada Sedimentary Basin, edited by: Mossop, G. D. and Shetsen, I., Canadian Society of Petroleum Geologists and Alberta Research Council, Alberta, chap. 17, 227-296, 1994.

Spence, G. D. and McLean, N. A.: Crustal seismic velocity and density structure of the Intermontane and Coast belts, southwestern Cordillera, Can. J. Earth Sci., 35, 1362-1379, doi:10.1139/cjes35-12-1362, 1998.
Tingay, M. R. P., Müller, B., Reinecker, J., Heidbach, O., Wenzel, F., and Fleckenstein, P.: Understanding tectonic stress in the oil patch: the World Stress Map project, The Leading Edge, 24, 1276-1282, doi:10.1190/1.2149653, 2005.

Turcotte, D. L. and Schubert, G.: Geodynamics, Cambridge University Press, 2002.

USGS: GTOPO30 - Global Land Survey Digital Elevation Model (GLSDEM), available at: https://lta.cr.usgs.gov/ GTOPO30, 2008.

Van Wees, J. D., Orlic, B., Van Eijs, R., Zijl, W., Jongerius, P., Schreppers, G. J., Hendriks, M., and Cornu, T.: Integrated 3D geomechanical modelling for deep subsurface deformation: a case study of tectonic and human-induced deformation in the eastern Netherlands, Geol. Soc. Spec. Publ., 212, 313-328, doi:10.1144/GSL.SP.2003.212.01.21, 2003.

Wang, Z., Nur, A., and Ebrom, D.: Seismic and Acoustic Velocities in Reservoir Rocks: Volume 3, Recent Developments, Expl. Geophys, 3, 2000.

Warpinski, N.: Determining the minimum in situ stress from hydraulic fracturing through perforations, Int. J. Rock Mech. Min., 26, 523-531, doi:10.1016/0148-9062(89)91430-7, 1989.

Weides, S. and Majorowicz, J.: Implications of spatial variability in heat flow for geothermal resource evaluation in large foreland basins: the case of the Western Canada Sedimentary Basin, Energies, 7, 2573-2594, doi:10.3390/en7042573, 2014.

Weides, S., Moeck, I., Majorowicz, J., Palombi, D., Grobe, M., and Mareschal, J.-C.: Geothermal exploration of Paleozoic formations in Central Alberta, Can. J. Earth Sci., 50, 519-534, doi:10.1139/cjes-2012-0137, 2013.

Weides, S., Moeck, I., Majorowicz, J., and Grobe, M.: The Cambrian Basal Sandstone Unit in central Alberta - an investigation of temperature distribution, petrography and hydraulic and geomechanical properties of a deep saline aquifer, Can. J. Earth Sci.,51, 783-796, doi:10.1139/cjes-2014-0011, 2014.

Welford, J. K., Clowes, R. M., Ellis, R. M., Spence, G. D., Asudeh, I., and Hajnal, Z.: Lithospheric structure across the craton-Cordilleran transition of northeastern British Columbia, Can. J. Earth Sci., 38, 1169-1189, doi:10.1111/j.1365246X.2006.02805.x, 2001.

Wessel, P., Smith, W. H. F., Scharroo, R., Luis, J., and Wobbe, F.: Generic mapping tools: improved version released, Eos T. Am. Geophys. Un., 94, 409-410, doi:10.1002/2013EO450001, 2013.

Wessling, S., Junker, R., Rutqvist, J., Silin, D., Sulzbacher, H., Tischner, T., and Tsang, C.-F.: Pressure analysis of the hydromechanical fracture behaviour in stimulated tight sedimentary geothermal reservoirs, Geothermics, 38, 211-226, doi:10.1016/j.geothermics.2008.10.003, 2009.

White, A. J., Traugott, M. O., and Swarbrick, R. E.: The use of leakoff tests as means of predicting minimum in-situ stress, Petrol. Geosci., 8, 189-193, doi:10.1144/petgeo.8.2.189, 2002.

White, D. J., Thomas, M., Jones, A., Hope, J., Németh, B., and Hajnal, Z.: Geophysical transect across a Paleoproterozoic continent continent collision zone: the Trans-Hudson Orogen, Can. J. Earth Sci., 42, 385-402, doi:10.1139/E05-002, 2005.

Woodland, D. and Bell, J. S.: In situ stress magnitudes from minifrac records in Western Canada, J. Can. Petrol. Technol., 28, 22-31, doi:10.2118/89-05-01, 1989.

Wright, G., McMechan, M., and Potter, D.: Structure and architecture of the Western Canada Sedimentary Basin, in: Geolog- 
ical Atlas of the Western Canada Sedimentary Basin, edited by: Mossop, G. D. and Shetsen, I., Canadian Society of Petroleum Geologists and Alberta Research Council, chap. 3, 25-40, 1994.

Yassir, N. A. and Bell, J. S.: Relationships between pore pressure, stresses, and present-day geodynamics in the Scotian Shelf, offshore eastern Canada, AAPG Bull., 78, 1863-1880, 1994.

Zang, A. and Stephansson, O.: Stress Field of the Earth's Crust, Springer Netherlands, Dordrecht, doi:10.1007/978-14020-8444-7, 2010.

Zelt, C. A. and White, D. J.: Crustal structure and tectonics of the southeastern Canadian Cordillera, J. Geophys. Res., 100, 24255-24273, doi:10.1029/95JB02632, 1995.

Zhou, S.: A method of estimating horizontal principal stress magnitudes from stress-induced wellbore breakout and leak-off tests and its application to petroleum engineering, Petrol. Geosci., 3, 57-64, 1997.

Zoback, M. D.: Reservoir Geomechanics: Earth Stress and Rock Mechanics Applied to Exploration, Production and Wellbore Stability, Cambridge Press, 2007.

Zoback, M. D. and Zoback, M. L.: State of stress and intraplate earthquakes in the United States, Science, 213, 96-104, doi:10.1126/science.213.4503.96, 1981.

Zoback, M. D. and Zoback, M. L.: Tectonic stress field of North America and relative plate motions, in: Neotectonics of North America, edited by: Slemmons, D. B. and Engdahl, E. R., Geological Society of America, 339-366, 1991.
Zoback, M. D., Barton, C., Brudy, M., Castillo, D., Finkbeiner, T., Grollimund, B., Moos, D., Peska, P., Ward, C., and Wiprut, D.: Determination of stress orientation and magnitude in deep wells, Int. J. Rock Mech. Min., 40, 1049-1076, doi:10.1016/j.ijrmms.2003.07.001, 2003.

Zoback, M. L.: First- and second-order patterns of stress in the lithosphere: the World Stress Map project, J. Geophys. Res., 97, 11703-11728, doi:10.1029/92JB00132, 1992.

Zoback, M. L. and Mooney, W. D.: Lithospheric buoyancy and continental intraplate stresses, Int. Geol. Rev., 45, 95-118, doi:10.2747/0020-6814.45.2.95, 2003.

Zoback, M. L. and Zoback, M. D.: State of stress in the conterminous United States, J. Geophys. Res., 85, 6113-6156, 1980.

Zoback, M. L. and Zoback, M. D.: Tectonic stress field of the continental United States, in: Geophysical Framework of the Continental United States, edited by: Pakiser, L. and Mooney, W. D., vol. 172, Geological Society of America, geological edn., doi:10.1130/MEM172-p523, chap. 24, 523-540, 1989.

Zoback, M. L., Zoback, M. D., Adams, J. J., Assumpção, M., Bell, J. S., Bergman, E. A., Blümling, P., Brereton, N. R., Denham, D., Ding, J., Fuchs, K., Gay, N., Gregersen, S., Gupta, H. K., Gvishiani, A., Jacob, K., Klein, R., Knoll, P., Magee, M., Mercier, J. L., Müller, B. C., Paquin, C., Rajendran, K., Stephansson, O., Suarez, G., Suter, M., Udias, A., $\mathrm{Xu}, \mathrm{Z}$. H., and Zhizhin, M.: Global patterns of tectonic stress, Nature, 341, 291-298, doi:10.1038/341291a0, 1989. 